\title{
Article \\ Selenium-Containing Exopolysaccharides Isolated from the Culture Medium of Lentinula edodes: Structure and Biological Activity
}

\author{
Sandra Górska-Jakubowska ${ }^{1}\left(\mathbb{D}\right.$, , Marzenna Klimaszewska $^{1}$, Piotr Podsadni ${ }^{1}$, Beata Kaleta ${ }^{2}(\mathbb{D}$, \\ Radosław Zagożdżon ${ }^{2}{ }^{(0)}$, Sabina Górska ${ }^{3}{ }^{\circledR}$, Andrzej Gamian ${ }^{4}{ }^{\circledR}$, Tomasz Strączek ${ }^{5}$, Czesław Kapusta ${ }^{6}$, \\ Marcin Cieślak ${ }^{7}$ (D) Julia Kaźmierczak-Barańska ${ }^{7}$, Barbara Nawrot ${ }^{7}$ iD and Jadwiga Turło ${ }^{1, *(D)}$
}

check for updates

Citation: Górska-Jakubowska, S.

Klimaszewska, M.; Podsadni, P.;

Kaleta, B.; Zagożdżon, R.; Górska, S.; Gamian, A.; Strączek, T.; Kapusta, C.; Cieślak, M.; et al.

Selenium-Containing

Exopolysaccharides Isolated from the Culture Medium of Lentinula edodes: Structure and Biological Activity. Int. J. Mol. Sci. 2021, 22, 13039. https:// doi.org/10.3390/ijms222313039

Academic Editors: Paolo Gualtieri and Laura Barsanti

Received: 4 November 2021

Accepted: 1 December 2021

Published: 2 December 2021

Publisher's Note: MDPI stays neutral with regard to jurisdictional claims in published maps and institutional affiliations.

Copyright: (c) 2021 by the authors. Licensee MDPI, Basel, Switzerland. This article is an open access article distributed under the terms and conditions of the Creative Commons Attribution (CC BY) license (https:// creativecommons.org/licenses/by/ $4.0 /)$.
1 Department of Drug Technology and Pharmaceutical Biotechnology, Medical University of Warsaw, 1 Banacha Str., 02-097 Warszawa, Poland; sandra.gorska@wum.edu.pl (S.G.-J.); marzenna.klimaszewska@wum.edu.pl (M.K.); ppodsadni@wum.edu.pl (P.P.)

2 Department of Clinical Immunology, Medical University of Warsaw, Nowogrodzka 59, 02-006 Warsaw, Poland; beata.kaleta@wum.edu.pl (B.K.); radoslaw.zagozdzon@wum.edu.pl (R.Z.)

3 Laboratory of Microbiome Immunology, Ludwik Hirszfeld Institute of Immunology and Experimental Therapy, Polish Academy of Sciences, Weigla 12, 53-114 Wroclaw, Poland; sabina.gorska@hirszfeld.pl

4 Laboratory of Medical Microbiology, Ludwik Hirszfeld Institute of Immunology and Experimental Therapy, Polish Academy of Sciences, Weigla 12, 53-114 Wroclaw, Poland; andrzej.gamian@hirszfeld.pl

5 Faculty of Mechanical Engineering and Robotics, AGH University of Science and Technology, Mickiewicza Av. 30, 30-059 Krakow, Poland; tsr@agh.edu.pl

6 Faculty of Physics and Applied Computer Science, AGH University of Science and Technology, Mickiewicza Av. 30, 30-059 Krakow, Poland; kapusta@agh.edu.pl

7 Centre of Molecular and Macromolecular Studies, Polish Academy of Sciences, Sienkiewicza 112, 90-363 Lodz, Poland; marcin@cbmm.lodz.pl (M.C.); juliakazmierczak@o2.pl (J.K.-B.); bnawrot@cbmm.lodz.pl (B.N.)

* Correspondence: jadwiga.turlo@wum.edu.pl

Abstract: In continuation of our research on the influence of selenium incorporation on the biosynthesis, structure, and immunomodulatory and antioxidant activities of polysaccharides of fungal origin, we have isolated from a post-culture medium of Lentinula edodes a selenium (Se)-containing exopolysaccharide fraction composed mainly of a highly branched 1-6- $\alpha$-mannoprotein of molecular weight $4.5 \times 10^{6} \mathrm{Da}$, with $15 \%$ protein component. The structure of this fraction resembled mannoproteins isolated from yeast and other mushroom cultures, but it was characterized by a significantly higher molecular weight. X-ray absorption fine structure spectral analysis in the near edge region (XANES) suggested that selenium in the Se-exopolysaccharide structure was present mainly at the IV oxidation state. The simulation analysis in the EXAFS region suggested the presence of two oxygen atoms in the region surrounding the selenium. On the grounds of our previous studies, we hypothesized that selenium-enriched exopolysaccharides would possess higher biological activity than the non-Se-enriched reference fraction. To perform structure-activity studies, we conducted the same tests of biological activity as for previously obtained mycelial Se-polyglucans. The Se-enriched exopolysaccharide fraction significantly enhanced cell viability when incubated with normal (human umbilical vein endothelial cells (HUVEC)) cells (but this effect was absent for malignant human cervical HeLa cells) and this fraction also protected the cells from oxidative stress conditions. The results of tests on the proliferation of human peripheral blood mononuclear cells suggested a selective immunosuppressive activity, like previously tested Se-polyglucans isolated from L. edodes mycelium. The Se-exopolysaccharide fraction, in concentrations of 10-100 $\mu \mathrm{g} / \mathrm{mL}$, inhibited human T lymphocyte proliferation induced by mitogens, without significant effects on B lymphocytes. As with previously obtained Se-polyglucans, in the currently tested Se-polymannans, the selenium content increased the biological activity. However, the activity of selenium exopolysaccharides in all tests was significantly lower than that of previously tested mycelial isolates, most likely due to a different mode of selenium binding and its higher degree of oxidation. 
Keywords: Lentinula edodes; selenopolysaccharides; selenoorganic compounds; Se-exopolysaccharides; mannans

\section{Introduction}

Mushroom-derived polysaccharides are compounds of various structure, variable functionality and diverse biological activity [1]. They are active as antioxidants and have antitumor, immunomodulating, antibacterial, antimicrobial, antiviral, anti-obesity, hypolipidemic, antidiabetic, and hepato-protective properties, among other activities [2-6]. Polysaccharides obtained from higher fungi affect different types of immune responses and are therefore collectively referred to as Biological Response Modifiers (BRM) [7]. In effect, several fungal polysaccharides are used as immunological adjuvants or as a non-invasive form of chemotherapy [8].

Numerous reports in the literature describe the analogous anti-tumor and immunomodulatory effects of some selenium compounds $[9,10]$. Selenium, as an active center of enzymes involved in oxidative transformations, plays a key role in the resistance mechanisms of plant and animal organisms [11]. A similar pharmacological effect of selenium and fungal polysaccharides, despite the difference in the mechanism, suggests the possibility of hyperadditive synergism (potentiation of action) of both components [12-17]. Therefore, it has been hypothesized that the introduction of selenium to the polysaccharide structure would increase the immunomodulatory activity. Although the increased activity of polysaccharides resulting from selenium incorporation has been confirmed by studies conducted in many research laboratories, the mechanism of this action is still unclear [18].

Lentinula edodes is a well-known edible and medicinal mushroom, from which lentinan, a branched $\beta$-D-glucan with immunomodulatory activity, has been isolated. Since the early 1980s lentinan has been used in several Asian countries as an adjuvant in cancer therapy [19-21]. However, some results of current clinical trials of lentinan are inconclusive and do not fully confirm its effectiveness [22,23].

In our previous research, we isolated a selenium-containing polysaccharide fraction from selenium-enriched mycelium of Lentinula edodes, using the method described for isolation of lentinan. We obtained Se-polysaccharides with so far undescribed structures: with selenium glycosidically bound in a polyglucoside chain or incorporated into the selenopyranose ring. The results concerning both the structure and the activity of the isolated Se-polysaccharides astonished us. Based on the literature data, we expected a selenated analogue of lentinan, that is (1-6),(1-3)- $\beta$-D-glucan, with incorporated selenium atoms, showing a immunostimulatory effect stronger than lentinan alone. However, the isolated Se-polysaccharides displayed unexpected structure and activity: selenated branched (1-3),(1-6)- $\beta$-D-glucans, linear (1-6)- $\beta$-D-glucans and (1-3)- $\beta$-D-glucans, with selective immunosuppressive activity $[24,25]$. The structure and activity of the isolated mycelial selenopolysaccharides probably resulted from the influence of selenium on polysaccharide biogenesis.

Mycelia of higher fungi may secrete so-called exopolysaccharides (EPS) into the culture medium [26], the secretion of which has been identified in the culture medium by L. edodes mycelial cultures [27-29]. These EPS have diverse structures and represent both homoand heteroglycans. They are composed mainly of units of glucose, mannose, galactose and xylose [30]. Interestingly, some of these compounds showed biological activities: e.g., antioxidant, immunomodulating, hypoglycemic, and others [31-34].

The aim of the present study was to investigate whether supplementation of the culture medium with selenium (in the form of sodium selenite, as in our previous research), would lead to incorporation of this element into the structure of exopolysaccharides secreted into the medium by mycelium of L. edodes. The designed research included the study of the primary structure of these compounds, the way selenium binds to the molecule, and the effect of selenation on the biological activity of EPS. To conduct the designed research, 
we used methods like those we used to study the structure and activity of selenopolysaccharides isolated from the L. edodes cell wall [24,25]. We intended to compare the structure, biological properties and, above all, the way selenium binds to the polysaccharide molecule in the Se-exopolysaccharides secreted into the medium by L. edodes mycelial cultures with the Se-polysaccharides previously isolated from the mycelium of this fungus. Therefore, we assumed that the same experimental conditions would ensure comparability of previously and currently obtained results.

\section{Results}

2.1. Isolation of Selenium-Containing Exopolysaccharides (Se-Exopolysaccharides)

In the case of mycelial L. edodes cultures enriched with $30 \mu \mathrm{g} / \mathrm{mL}$ of selenium (added to the medium in the form of sodium selenite), the average efficiency of the isolation of Se-exopolysaccharides from the post-culture medium was $8.1 \mathrm{mg} / \mathrm{L}$. For the reference cultures, cultivated in medium not enriched in selenium, the efficiency of isolation of exopolysaccharides was $25 \%$ lower, amounting to $6.1 \mathrm{mg} / \mathrm{L}$. Due to the deproteinization of the culture medium carried out before precipitation of the polysaccharide fractions with alcohol, the obtained result applies only to glycans and proteoglycans with a low share of the protein component.

\subsection{IR Spectral Analysis}

The FT-IR spectrum of the Se-exopolysaccharide fraction (Le-P-Se) is shown in Figure 1, while the FT-IR spectrum of the reference Le-P-0 fraction is shown in Figure 2.
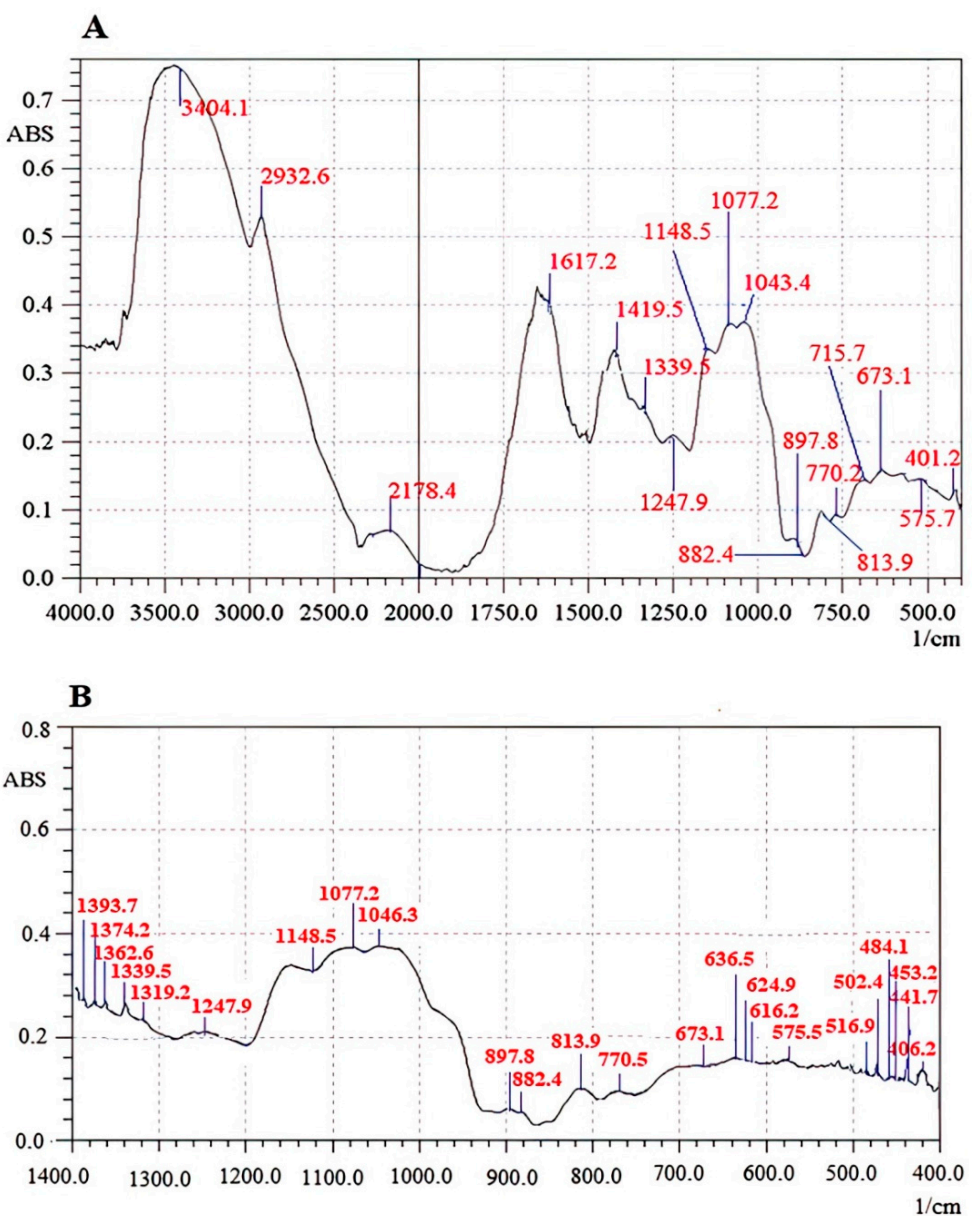

Figure 1. The FT-IR spectrum of the Se-exopolysaccharide fraction Le-P-Se. (A) In the scope of 4000.0 to $500.01 / \mathrm{cm}$. (B) In the scope of 1200.0 to $400.01 / \mathrm{cm}$. 


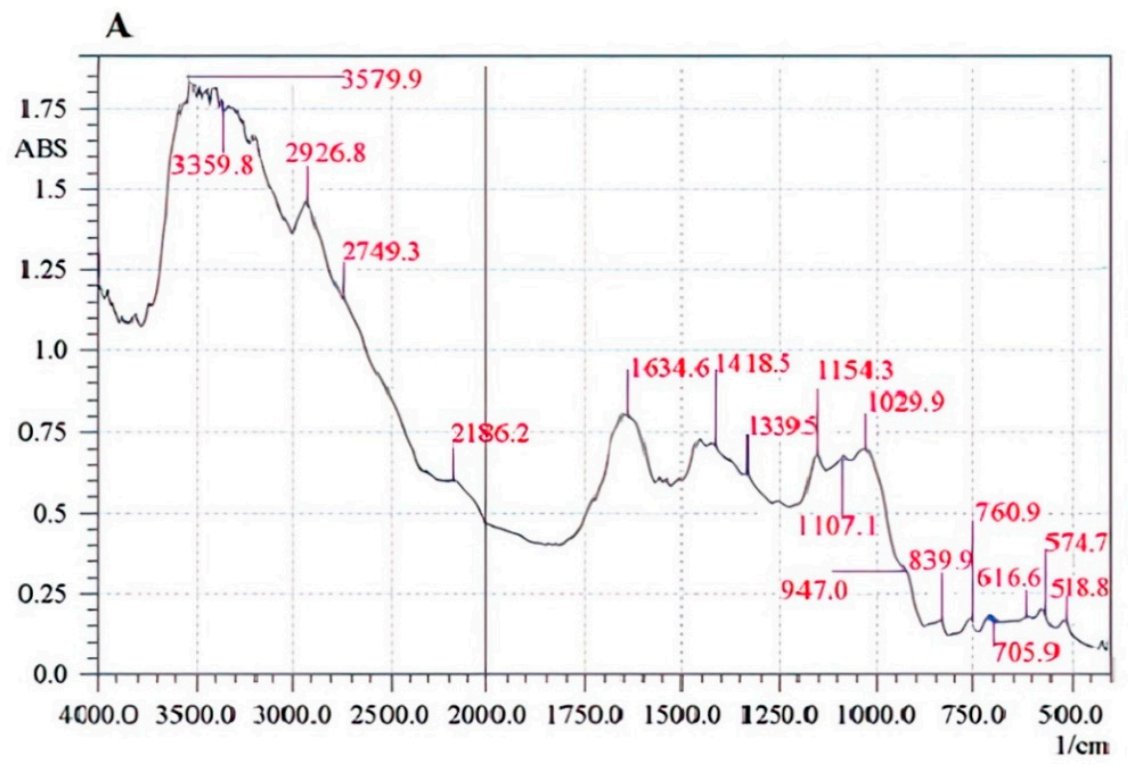

B

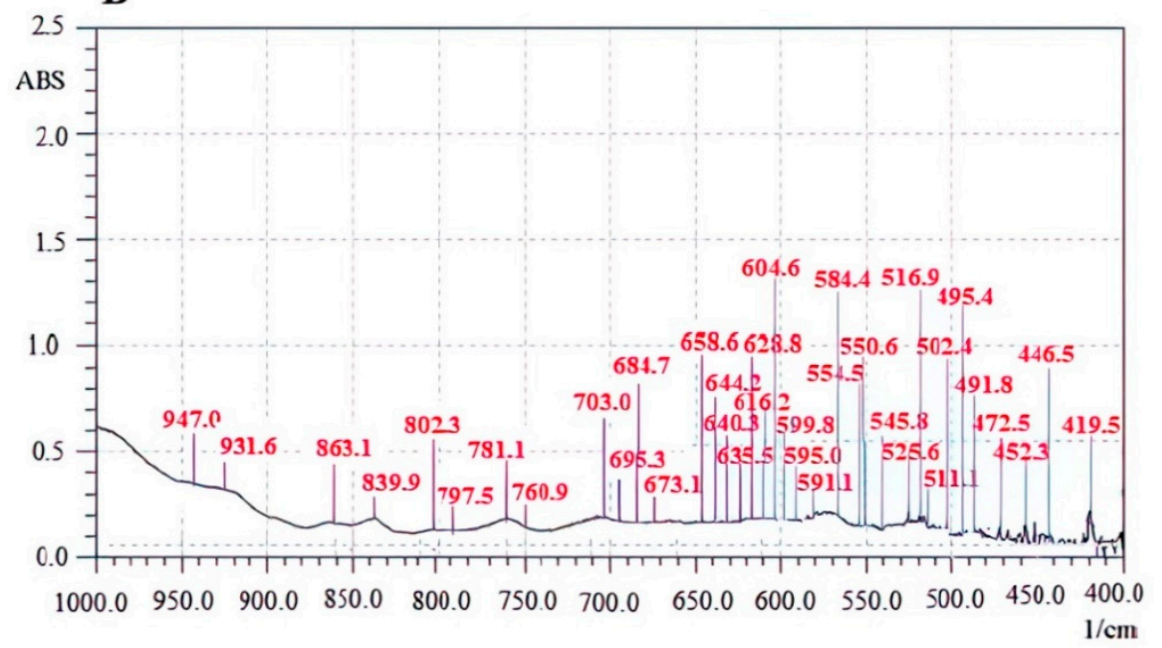

Figure 2. The FT-IR spectrum of the reference exopolysaccharide fraction Le-P-0. (A) In the scope of 4000.0 to $500.01 / \mathrm{cm}$. (B) In the scope of 1000.0 to $400.01 / \mathrm{cm}$.

The IR spectrum of Se-exopolysaccharide Le-P-Se displayed a characteristic band from $-\mathrm{OH}$ groups in the range of $3400 \mathrm{~cm}^{-1}$. The presence of the $-\mathrm{OH}$ stretching signal on the spectrum of reference exopolysaccharide Le-P-0 appeared in the region of $3580-3360 \mathrm{~cm}^{-1}$. A signal corresponding to $\mathrm{C}-\mathrm{H}$ stretching vibrations appeared in the region of $2932.6 \mathrm{~cm}^{-1}$ to $2700 \mathrm{~cm}^{-1}$. The $1617.2 \mathrm{~cm}^{-1}$ peak in the Le-P-Se spectrum and the $1634.6 \mathrm{~cm}^{-1}$ peak in the Le-P-0 were assigned to the amide vibrations of proteins [35]. In the $1250-1000 \mathrm{~cm}^{-1}$ range, stretching vibrations of $\mathrm{C}-\mathrm{OH}$ bonds and $\mathrm{C}-\mathrm{O}-\mathrm{C}$ glycosidic bonds dominated. The presence of the bands characteristic of the pyranose ring $\left(1077.2 \mathrm{~cm}^{-1}\right.$ and $\left.1107.1 \mathrm{~cm}^{-1}\right)$ was found [31-36]. The peaks attributed to the vibrations of the $\gamma \mathrm{C}-\mathrm{O}$ hydroxyl and acetal groups were found around 1339.5, 11,458.5, 1043.4, $715.7 \mathrm{~cm}^{-1}$ (Figure 1) and 1339.5, 1154.3, $1029.9,705.9 \mathrm{~cm}^{-1}$ (Figure 2) [37-41]. Based on the analysis of the spectra, both $\beta$ and $\alpha$ glycosidic bonds were detected. The weaker band at $897.8 \mathrm{~cm}^{-1}$ (Figure 1) was specific for $\beta$-glucans. However, the band located in the anomeric range at $813.9 \mathrm{~cm}^{-1}$ indicated the presence of $\alpha$-glycosidic bonds: the band bending beyond the $\mathrm{CH}$ bond plane in the region of $839.9 \mathrm{~cm}^{-1}$ (Figure 2) and $882.4 \mathrm{~cm}^{-1}$ (Figure 1), the band of symmetrical skeletal valence vibrations: $770.2 \mathrm{~cm}^{-1}$ (Figure 1) and $760.9 \mathrm{~cm}^{-1}$ and the band of asymmetric skeletal valence vibrations $947 \mathrm{~cm}^{-1}$ (Figure 2) [41,42]. 


\subsection{Homogeneity and Molecular Weight of the Exopolysaccharide Fraction}

The types of glycosidic linkages in the Se-enriched and non-Se-enriched exopolysaccharide fractions were identified by the IR spectra as mainly $\alpha$ - and also $\beta$-. Thus, we decided to use both commercially available $\alpha$ - and $\beta$-glucan standards (Megazyme) to create the calibration curves obtained by plotting molecular weight (Mp-molecular weight corresponding to that of the maximum of the chromatographic peak) versus time (Figures 3 and 4). The molecular weight of the Le-P-Se fraction determined on grounds of the standard curve for $\beta$-glucans (Figure 3) was $2630 \mathrm{kDa}$, while for the $\alpha$-glucans, the value was $-4468 \mathrm{kDa}$. Mp values for the reference samples were $954 \mathrm{kDa}$ and $2570 \mathrm{kDa}$, respectively. The reported result is the mean, the number of replicates (n) was 3, and the relative standard deviation (RSD) was $\leq 5 \%$.The determined molar mass, however, should be treated as an uncertain value, despite the high value of the correlation coefficients of the standard curves $\left(R^{2}=0.9859\right.$ for $\beta$-glucans and $R^{2}=0.9989$ for $\alpha$-glucans $)$, because the elution volume of the examined fractions was significantly lower than that of all commercially available standards. Therefore, the resulting molar mass value was obtained by extrapolation of the calibration curve, resulting in considerable uncertainty of the result. The problem may also arise from the fact that the retention volume in gel permeation chromatography is also influenced (apart from the molar mass) by differences in the spatial structure of the molecules.

\subsection{The Total Selenium Content}

The concentration of selenium in the crude Se-exopolysaccharide fraction Le-P-Se was $582.4 \mu \mathrm{g} / \mathrm{g}$, whereas in that purified by the Yap and Ng method, it was $219.05 \mu \mathrm{g} / \mathrm{g}$ [43].

\subsection{Total Protein Content and Amino Acid Composition}

The total protein content of the Se-enriched exopolysaccharide fraction and the reference (not-Se-enriched exopolysaccharide) was determined by three different methods: the Bradford method, on grounds of the elemental analysis of nitrogen content, and as a sum of the amino acid masses. After the Sevage deproteinization process, the protein content determined by Bradford method in the reference fraction Le-P-Se was lower by $2.23 \%$ than in the Le-P-0 fraction and equaled $168.50 \mathrm{mg} / \mathrm{g}$ vs. $172.25 \mathrm{mg} / \mathrm{g}$. The percentage of nitrogen in Le-P-Se and Le-P-0 fractions, determined by elemental analysis was $2.88 \%$ and $2.98 \%$, respectively, which corresponds to $180.21 \mathrm{mg} / \mathrm{g}$ and $186.29 \mathrm{mg} / \mathrm{g}$. The results of determining the content of amino acids in the polysaccharide fractions, after acid hydrolysis, by high-performance liquid chromatography (HPLC), in turn, showed a higher content of amino acids in the selenium-enriched polysaccharide fraction than in the reference $(149,671 \mathrm{mg} / \mathrm{g}$ vs. $144,625 \mathrm{mg} / \mathrm{g})$. In both exopolysaccharide fractions, the main amino acids in the protein component were: arginine, leucine, serine, and valine (Figure 5). The selenium-containing amino acid selenomethionine was found in both fractions. The content of selenomethionine in the Le-P-Se fraction was significantly higher $(0.353 \mathrm{mg} / \mathrm{g})$.

The differences in the results obtained by the different methods of determining the protein content were expected by us, due to the incomplete selectivity of the methods used. Even the chromatographic method of determining the amino acids in the protein hydrolysate is burdened with a certain error, due to the impossibility of determining the proline and hydroxyproline by the OPA method; however, we considered this result to be the most reliable. In summary, it can be assumed that the protein content in the selenium and non-selenated fraction is within $15-18 \%$. 

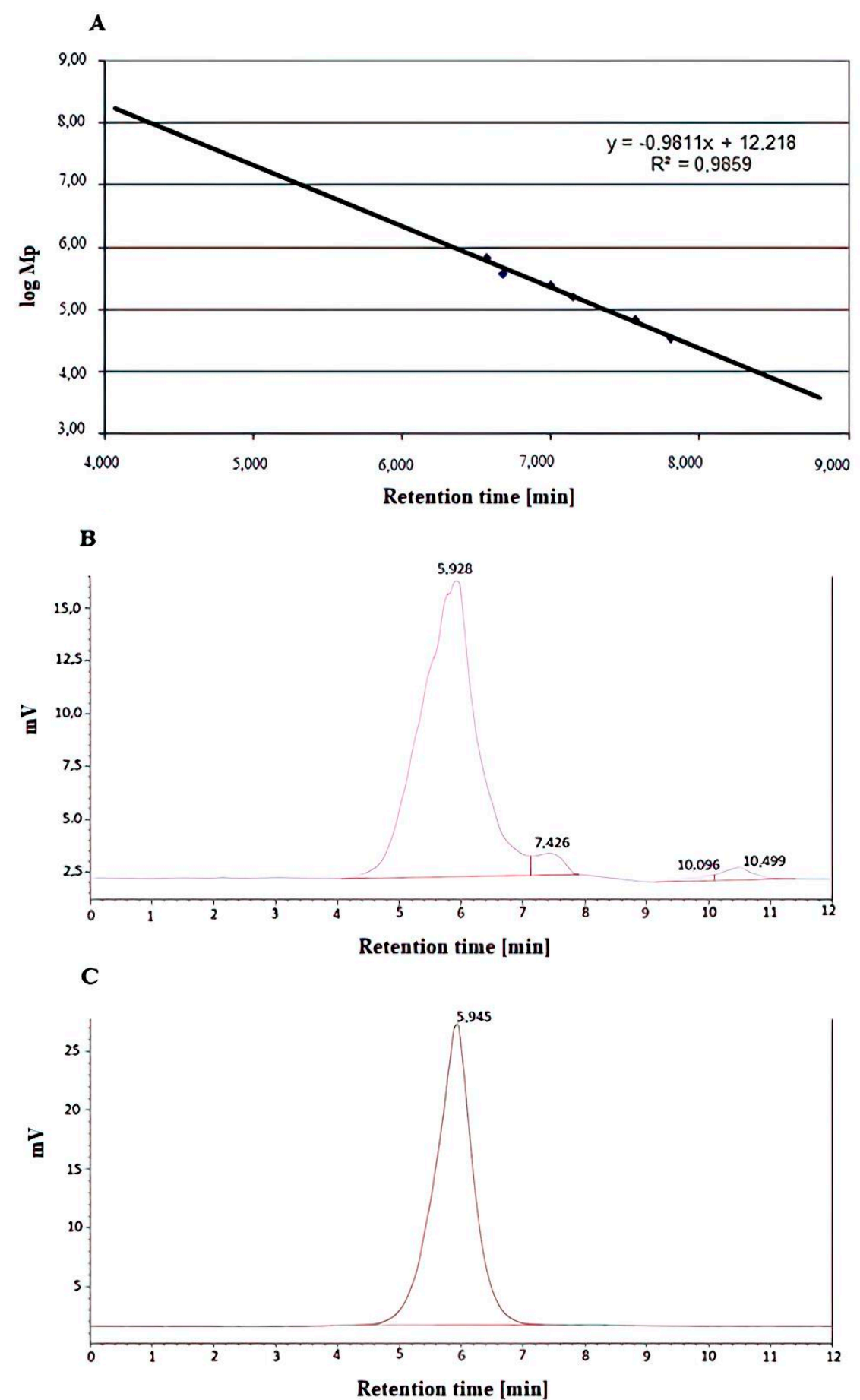

Figure 3. (A) Molecular weight distribution of standard $\beta$-glucans. (B) Chromatogram of the Le-P-0 fraction. (C) Chromatogram of the Le-P-Se fraction. Conditions: injection of $20 \mu \mathrm{L}$ at a concentration of $1 \mathrm{mg} / \mathrm{mL}$ of the analyte, using a TSK gel Super Multipore PW-H $6.0 \mathrm{~mm}$ ID $\times 150 \mathrm{~mm}$ (TOSOH Bioscience) brand column eluted with ultrapure water (Merck, Darmstadt) as the mobile phase at a flow rate of $0.4 \mathrm{~mL} / \mathrm{min}$ and conditioned at $50{ }^{\circ} \mathrm{C}$. Mp: molecular weight corresponding to the maximum chromatographic peak. 
$\mathbf{A}$

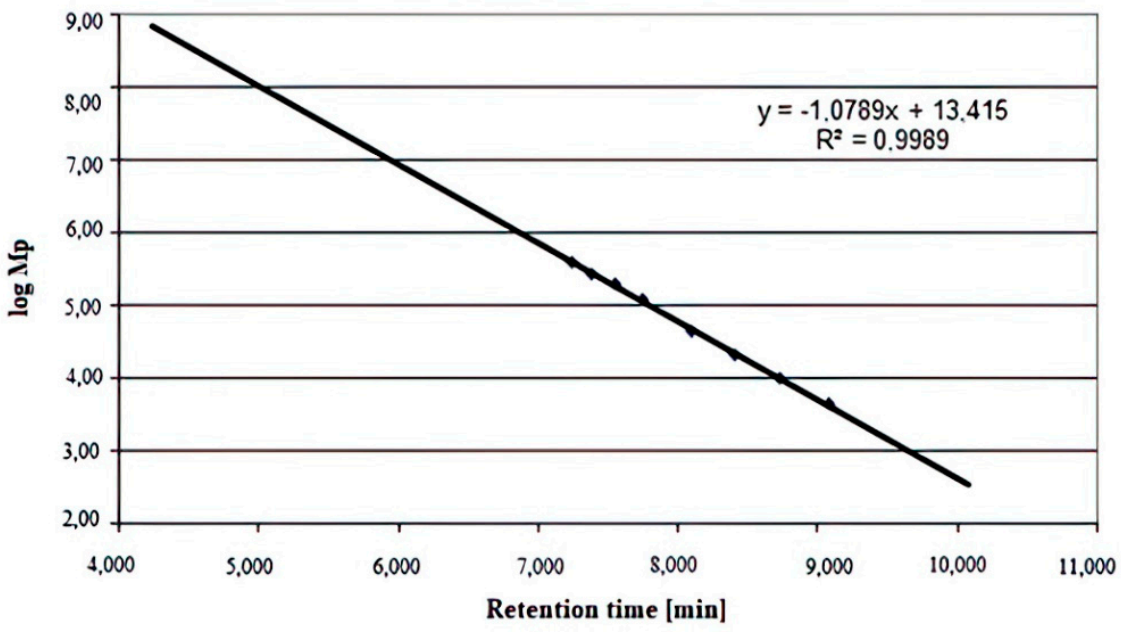

B
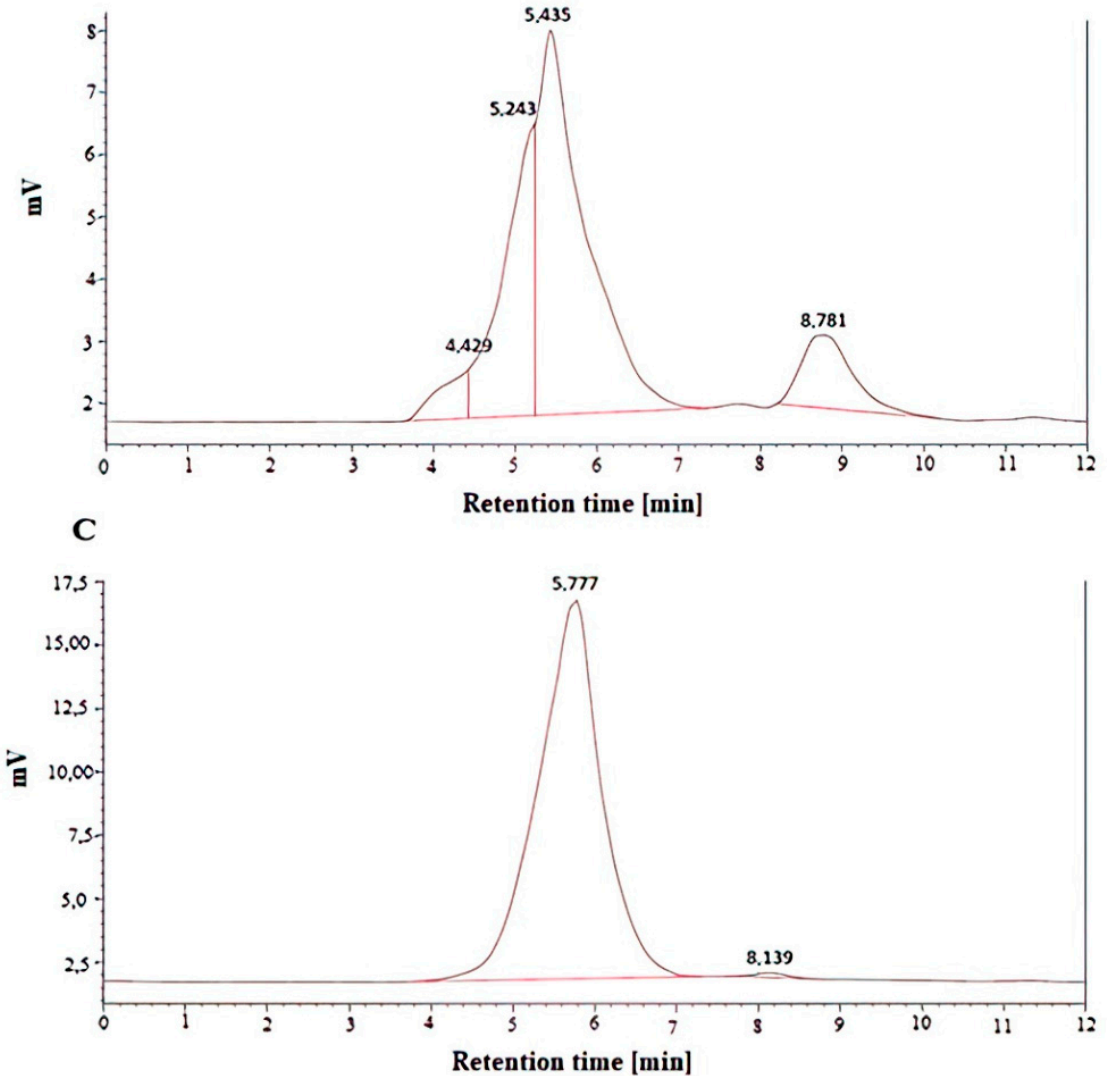

Figure 4. (A) Molecular weight distribution of standard $\alpha$-glucans. (B) Chromatogram of Le-P-0 fraction. (C) Chromatogram of the Le-P-Se fraction. Conditions: injection of $20 \mu \mathrm{L}$ at a concentration of $1 \mathrm{mg} / \mathrm{mL}$ of the analyte, using a TSK gel Super Multipore PW-H $6.0 \mathrm{~mm}$ ID $\times 150 \mathrm{~mm}$ (TOSOH Bioscience) brand column eluted with ultrapure water (Merck, Darmstadt) as the mobile phase at a flow rate of $0.4 \mathrm{~mL} / \mathrm{min}$ and conditioned at $50{ }^{\circ} \mathrm{C}$. Mp: molecular weight corresponding to the maximum of the chromatographic peak. 


\section{- Le-P-Se $\square$ Le-P-0}

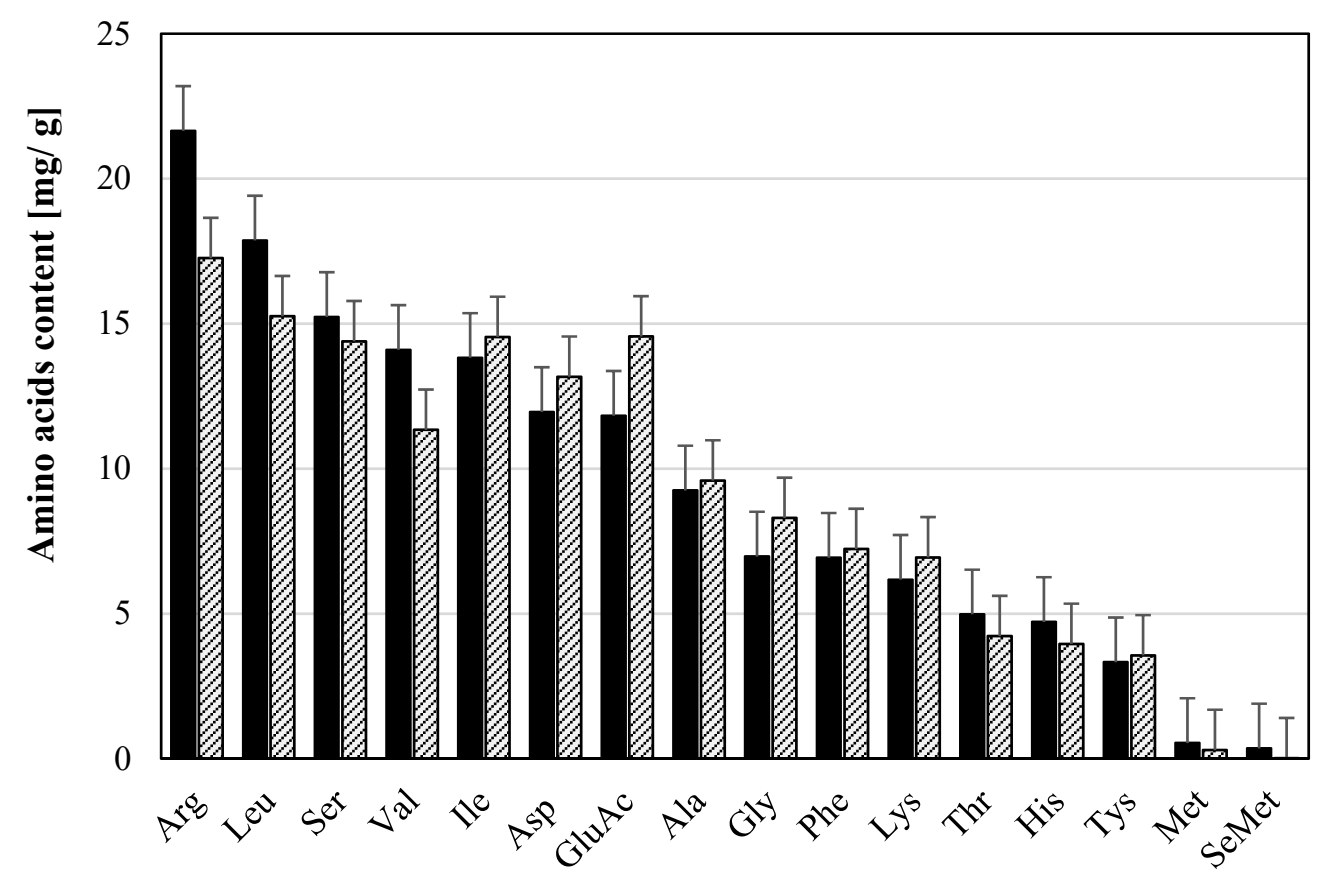

Figure 5. Amino acid composition of Se-exopolysaccharides and the reference fraction.

\subsection{Monosaccharide Composition of Se-Exopolysaccharides}

The monosaccharide composition of the crude Se-enriched exopolysaccharide and the reference fractions was determined after complete hydrolysis with trifluoroacetic acid (TFA) [44]. In both exopolysaccharide fractions, the main monosaccharides were mannose, galactose, and glucose. These three monosaccharides constituted $91.44 \%$ of the total amount by weight. In the reference fraction, glucose, mannose, and galactose accounted for $90.57 \%$. The differences in the monosaccharide composition of Se-exopolysaccharides and the reference fraction (Figure 6) were minimal.

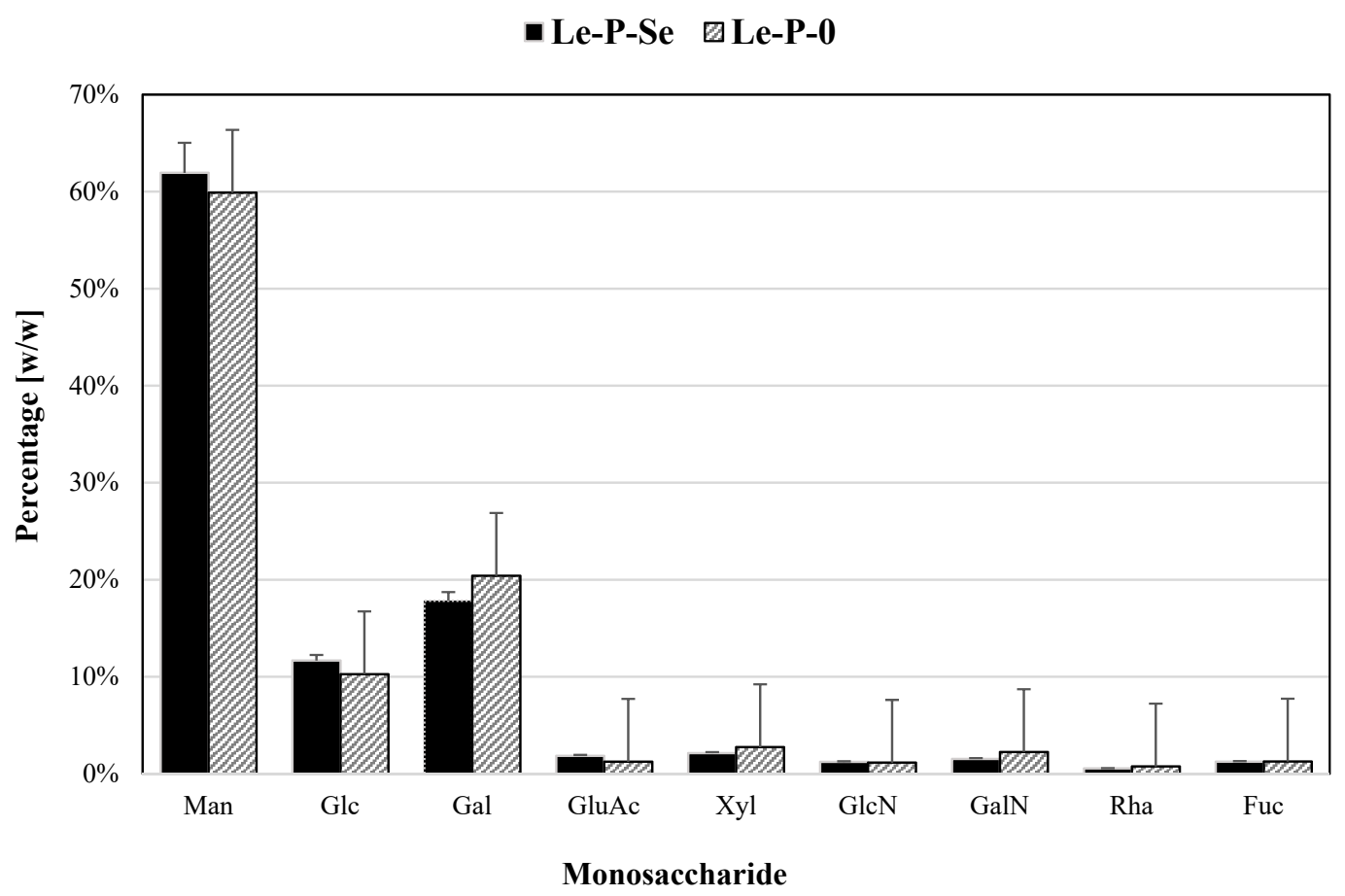

Figure 6. Monosaccharide composition of the crude Se-exopolysaccharide Le-P-Se and the reference fraction Le-P-0. 
After purification of the crude Le-P-Se and Le-P-0 fractions with the Yap and Ng method [43], practically only mannose $(89 \%)$ with a slight addition of glucose (in the case of the non-selenated fraction) remained in both fractions.

\subsection{NMR Spectral Analysis}

The chemical shifts were assigned utilizing COSY, TOCSY, NOESY, HSQC, and HMBC experiments (Table 1). Anomeric configurations were assigned on the basis of the chemical shifts of ${ }^{3} J_{\mathrm{H}-1, \mathrm{H}-2}$ and ${ }^{1} J_{\mathrm{C}-1, \mathrm{H}-1}$ values as well as by comparison with previously published NMR data [45-47]. Based on the COSY and TOCSY spectrum from the $\mathrm{H}-2$ proton signal for all of the spin systems, it was possible to assign all of the resonances, and from these, all the ${ }^{13} \mathrm{C}$ resonances from the HSQC spectrum. The ${ }^{1} \mathrm{H}_{-}{ }^{13} \mathrm{C}$ HSQC-DEPT NMR spectrum (Figure 7) of the Le-P-Se fraction contained five anomeric proton signals: residues A, B, C, $\mathrm{D}, \mathrm{E}$ at $\delta_{\mathrm{H}} 5.32,5.22,5.06,5.03,4.97 \mathrm{ppm}$, respectively, while the same residues correlated with carbon resonances at $\delta_{C} 99.7,101.0,102.8,99.3,102.6 \mathrm{ppm}$, respectively.

Table 1. ${ }^{1} \mathrm{H}$ and ${ }^{13} \mathrm{C}$ NMR chemical shifts of sample Se-exopolysaccharides fraction.

\begin{tabular}{|c|c|c|c|c|c|c|c|}
\hline & \multicolumn{7}{|c|}{ Chemical Shifts ${ }^{1} \mathrm{H},{ }^{13} \mathrm{C}(\mathrm{ppm})$. } \\
\hline & H1 & $\mathrm{H} 2$ & H3 & H4 & H5 & H6 & $\mathbf{H} \mathbf{6}^{\prime}$ \\
\hline Sugar residue & $\mathrm{C} 1$ & $\mathrm{C} 2$ & $\mathrm{C} 3$ & $\mathrm{C} 4$ & C5 & C6 & \\
\hline $\mathrm{A}$ & 5.32 & 3.54 & 3.88 & 3.58 & 3.75 & 3.75 & \\
\hline$\rightarrow 4)-\alpha$-D-Glc $p$ - $(1 \rightarrow$ & 99.7 & 71.5 & 73.3 & 76.7 & 71.1 & 60.4 & \\
\hline B & 5.22 & 4.04 & 3.82 & 3.67 & 3.70 & $3.82 / 3.66$ & 5.22 \\
\hline$\rightarrow 2)-\alpha-\mathrm{D}-\mathrm{Man} p-(1 \rightarrow$ & 101.0 & 79.0 & 70.7 & 66.7 & 73.8 & 61.5 & \\
\hline $\mathrm{C}$ & 5.06 & 3.98 & 3.86 & 3.68 & 3.71 & $3.82 / 3$ & 3.66 \\
\hline$\rightarrow 3)-\alpha-\mathrm{D}-\mathrm{Man} p-(1 \rightarrow$ & 102.8 & 70.6 & 78.3 & 66.7 & 73.9 & 61.5 & \\
\hline $\mathrm{D}$ & 5.03 & 3.95 & 3.78 & 3.60 & 3.94 & $3.94 / 3$ & 3.59 \\
\hline$\rightarrow 2,6)-\alpha-\mathrm{D}-M a n p-(1 \rightarrow$ & 99.3 & 79.1 & 70.8 & 67.2 & 73.7 & 66.1 & \\
\hline $\mathrm{E}$ & 4.97 & 4.14 & 3.85 & 3.73 & 3.68 & $3.82 / 3$ & 3.66 \\
\hline$\alpha$-D-Man $p-(1 \rightarrow$ & 102.6 & 70.1 & 70.9 & 66.8 & 73.4 & 61.5 & \\
\hline
\end{tabular}

Spectra were obtained for ${ }^{2} \mathrm{H}_{2} \mathrm{O}$ solutions at $25^{\circ} \mathrm{C}$, and acetone $\left(\delta_{\mathrm{H}} 2.225, \delta_{\mathrm{C}} 31.05 \mathrm{ppm}\right)$ was used as an internal reference.

Present only in the Le-P-0 exopolysaccharide fraction residue, $\mathbf{A}$ had the proton chemical signal at $\delta_{\mathrm{H}} 5.32 \mathrm{ppm}$ and the carbon chemical shift at $\delta_{\mathrm{C}} 99.7 \mathrm{ppm}$ and the coupling constants values ${ }^{3} J_{\mathrm{H}-1, \mathrm{H}-2}(\sim 3.6 \mathrm{~Hz})$ and ${ }^{3} J_{\mathrm{C}-1, \mathrm{H}-1}(\sim 172 \mathrm{~Hz})$. These data suggested that residue $\mathbf{A}$ was $\alpha$-linked. The downfield shift of C-4 (76.7 ppm) of $\mathbf{A}$ indicated that this is a $\rightarrow 4)-\alpha$-D-Glc $p$ - $(1 \rightarrow$ residue $[48,49]$. The connectivities were found between C- 1 of $\mathbf{A}$ and $\mathbf{C}-4$ of $\mathbf{A}$. We did not observed any cross-peaks between residue $\mathbf{A}$ and other residues, and thus we determined that this is a separate polymer: $\alpha-1,4$-glucan.

Other signals were identified as possessing an $\alpha$-manno configuration (low value of ${ }^{3} J_{\mathrm{H}-1, \mathrm{H}-2}$ and ${ }^{1} J_{\mathrm{C}-1, \mathrm{H}-1)}$ and represented the different mannose residues. The downfield shifts of C-2 (79.0 ppm) of residue B indicated that it was a $\rightarrow 2)-\alpha-D-M a n p-(1 \rightarrow$ residue [50], whereas downfield shifts of $C-3(78.3 \mathrm{ppm})$ of residue $\mathbf{C}$ pointed towards it being a $\rightarrow 3)-\alpha$-D-Man $p$ - $(1 \rightarrow$ residue. Furthemore, residue $\mathbf{D}$ possessed C-2 $(79.1 \mathrm{ppm})$ and C-6 (66.1 ppm) chemical shifts at low fields owing to glycosylation, and was therefore identified as a $\rightarrow 2,6)-\alpha$-D-Man $p$-( $1 \rightarrow$ residue. Likewise, at $4.97 \mathrm{ppm}$ (residue E), it was possible to identify non-substituted mannose residues as inferred by their ${ }^{1} \mathrm{H}$ and ${ }^{13} \mathrm{C}$ resonances. It must be underscored that a very weak signal at the level of the noise appeared at $\delta_{\mathrm{H}} / \delta_{\mathrm{C}} 4.88 / 99.1 \mathrm{ppm}$. This signal was proposed to represent another $\alpha$-mannose, probably $\rightarrow 6)-\alpha$-D-Man $p$ - $(1 \rightarrow$ according to previously presented mannan data in the literature [51,52]. However, the very low intensity of the signals did not allow identification of the consecutive cross peaks in the NMR spectra, and thus, the interpretation of the 
linkage types remained ambiguous. The sequence of the monosaccharide residues within the repeating unit of the polysaccharides was obtained by assignment of the inter-residue interactions observed in the 2D NOESY and HMBC spectra.

$\mathbf{A}$

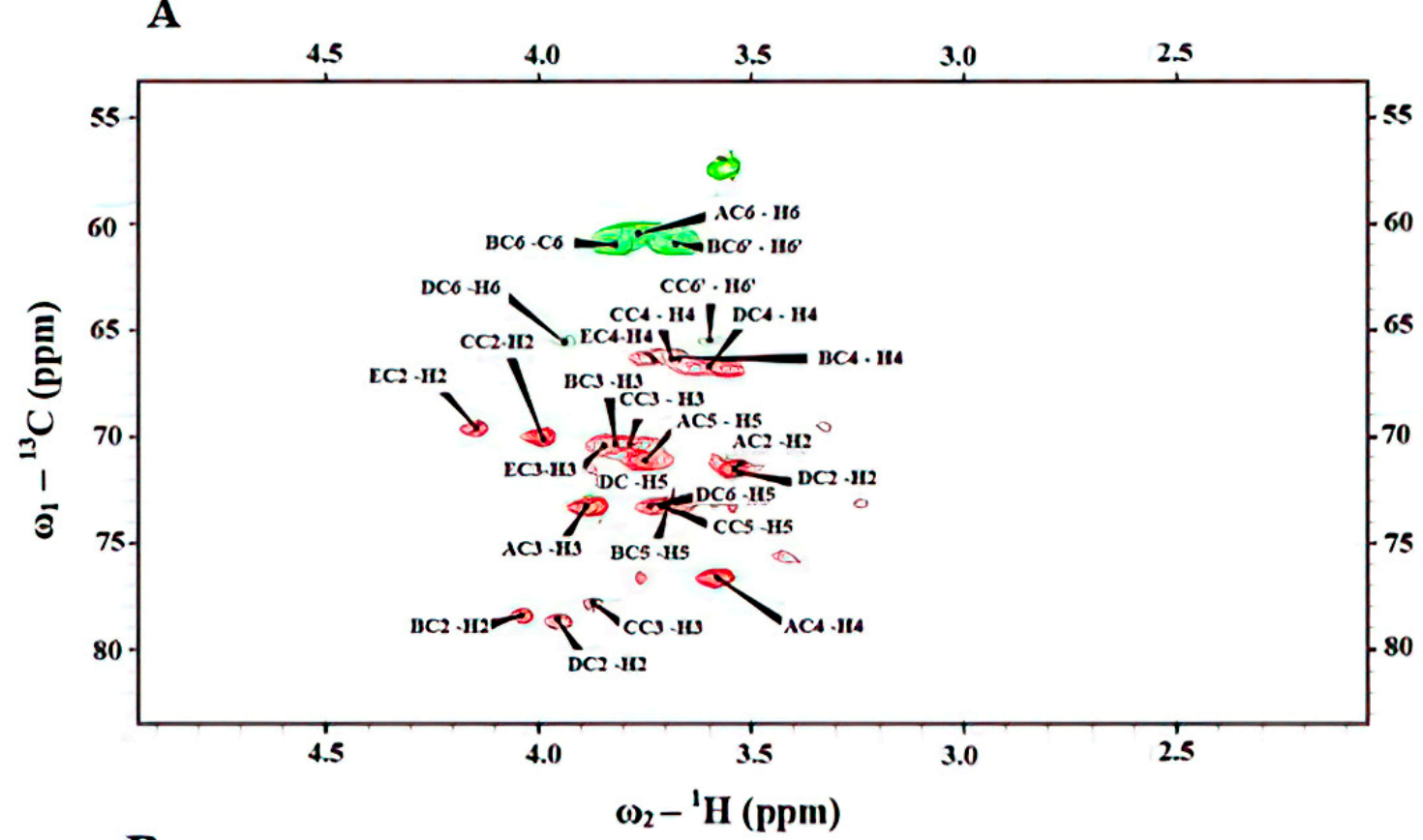

B

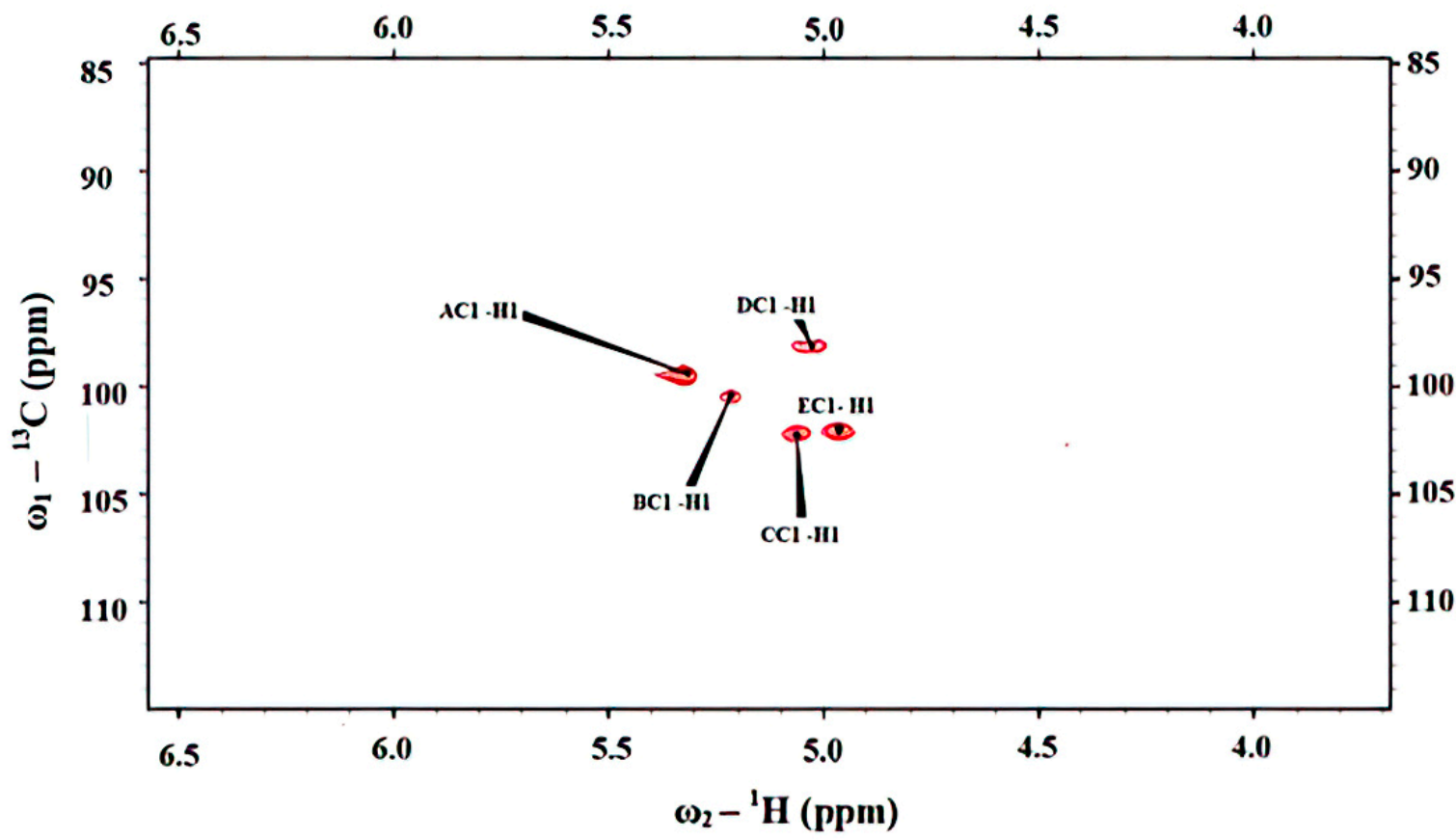

Figure 7. Selected parts of the ${ }^{1} \mathrm{H}_{-}{ }^{13} \mathrm{C}$ HSQC NMR spectra of exopolysaccharides. Selected parts of the ${ }^{1} \mathrm{H}_{-}{ }^{13} \mathrm{C} \mathrm{HSQC} \mathrm{NMR}$ spectra of exopolysaccharides: (A) region of ring carbons (green colors-negative signals for the $\mathrm{CH} 2$, red color-positive signals for the $\mathrm{CH}$ carbons), (B) region of anomeric carbons in the ring.

The structure was identified as a highly branched $\alpha$-mannan. The connectivities were found between $\mathbf{C}-1$ of $\mathbf{D}$ and $\mathbf{C}-6$ of $\mathbf{D}, \mathbf{C}-1$ of $\mathbf{B}$ and $\mathbf{C}-2$ of $\mathbf{D}, \mathbf{C}-1$ of $\mathbf{C}$ and $\mathbf{C}-2$ of $\mathbf{B}$, and $\mathbf{C}-1$ of $\mathbf{E}$ and $\mathbf{C}-3$ of $\mathbf{C}$ and $\mathbf{C}-2$ of $\mathbf{B}$. Based on the already published mannan polysaccharides $[53,54]$, it was clear that the structure could be presented as follows (Figure 8): 


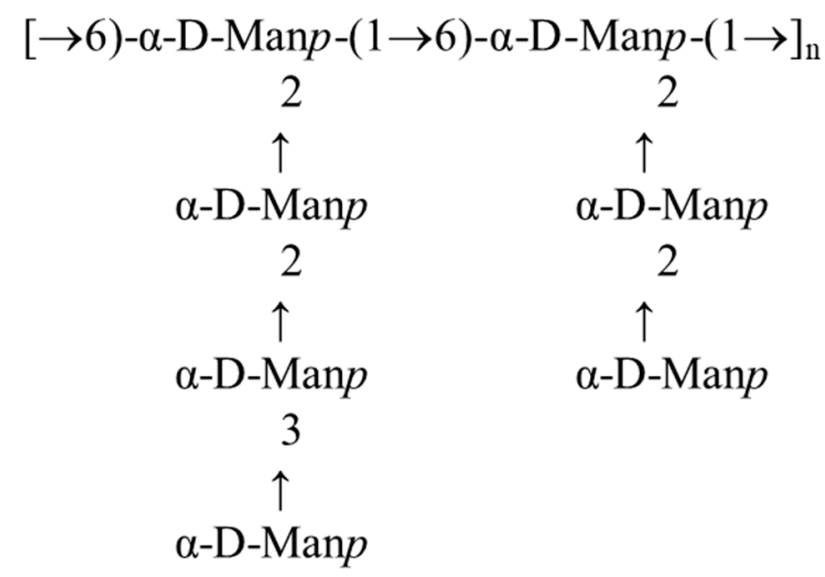

Figure 8. Structure of the highly branched $\alpha$-D-mannan constituting the main component of the Le-P-Se and Le-P-0 fractions.

The structures of the selenium-enriched and non-selenium-enriched exopolysaccharide fractions are identical except for the presence of a low amount of $\alpha$-glucan in the non-selenated fraction.

\subsection{X-ray Absorption Spectroscopy (XAS) Determination of Se Oxidation State and Chemical Speciation}

The exopolysaccharide fraction containing selenium (Le-P-Se) and samples of standard selenium compounds with different degrees of oxidation (reference samples) were analyzed by the XAS method in the X-ray absorption near-edge structure (XANES) range. XANES analysis allows the determination of the average degree of oxidation of an element in the tested sample by determining the energy of the absorption threshold. This energy is related to the chemical shift $\mu$. It is normally defined as the maximum of the first derivative of the dependence of absorption on the energy of the incident beam of radiation (Figure 9). The values of the obtained edge energy shifts in relation to the value measured for the tested sample Le-P-Se, and the reference samples (Se 0, Se II and Se IV) are presented in Table 2.

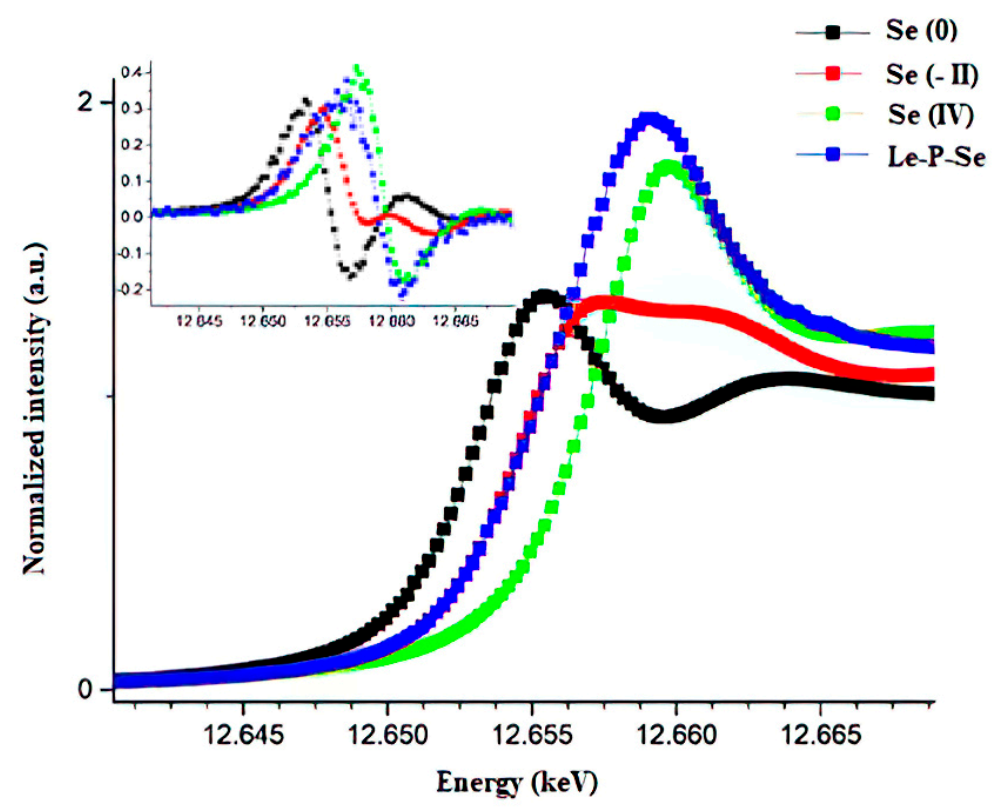

Figure 9. Edge step normalized selenium K edge XANES spectra for the experimental and reference samples. The insert presents their first derivatives: Se (-II)—selenomethionine reference compounds for organically bound Se (-II), Se 0-elemental red selenium powder as reference for Se (0), Se-IVsodium selenite $\left(\mathrm{Na}_{2} \mathrm{SeO}_{3}\right.$ as reference for Se (IV)), Le-P-Se-Se-exopolysaccharide fraction. 
Table 2. Edge energy values for the experimental samples and reference samples.

\begin{tabular}{ccc}
\hline Sample & E & E-E0 \\
\hline Le-P-Se & $12,656.9$ & 3.6 \\
Se 0 & $12,653.3$ & 0.0 \\
Se-II & $12,654.6$ & 1.3 \\
Se IV & $12,657.5$ & 4.2
\end{tabular}

E-Edge energy values for the experimental samples, E0-Edge energy value for the elemental red selenium sample, Le-P-Se-Se-exopolysaccharide fraction, Se(-II)-selenomethionine reference compounds for organically bound $\mathrm{Se}(-\mathrm{II})$, Se 0 —elemental red selenium powder as reference for $\mathrm{Se}(0)$, Se-IV-sodium selenite $\left(\mathrm{Na}_{2} \mathrm{SeO}_{3}\right.$ as reference for Se (IV)).

Comparison of the energy of the absorption threshold of the tested sample against Se 0 and Se IV (E-E0) suggested that selenium in the tested sample is at an average oxidation state of IV and the lower absorption edge energy is related to a different neighborhood than in the sodium selenite. The presence of a strong "white line" (the line at the energy immediately above the absorption edge) suggested that in sample Le-P-Se, selenium has oxygen in the immediate vicinity, as in the standard sodium selenite sample. The intensity of the white line is related to the number of empty electron states above the Fermi energy [55]. For the selenomethionine sample, where the closest selenium neighbor is carbon, there is no clear white line, which is related to the degree of covalent bonding that is greater with Se-C than with Se-O.

\subsection{Extended X-ray Absorption Fine Structure (EXAFS) Analysis of the Local Structure around} Se in Se-Exopolysaccharide

EXAFS analysis provides information about the distribution structure of atoms in the vicinity of the absorbing atom. The analysis uses the phenomenon of oscillation of the absorption coefficient at energies above the absorption threshold due to the presence of adjacent atoms (interference of the emitted photoelectron wave reflected from the atoms with the part originating from the exciting atom). By separating these oscillations from the rest of the signal, one can analyze the "frequencies" of these oscillations that correspond to the distances of neighboring atoms [56]. The EXAFS functions of the tested samples are shown in Figure 10.

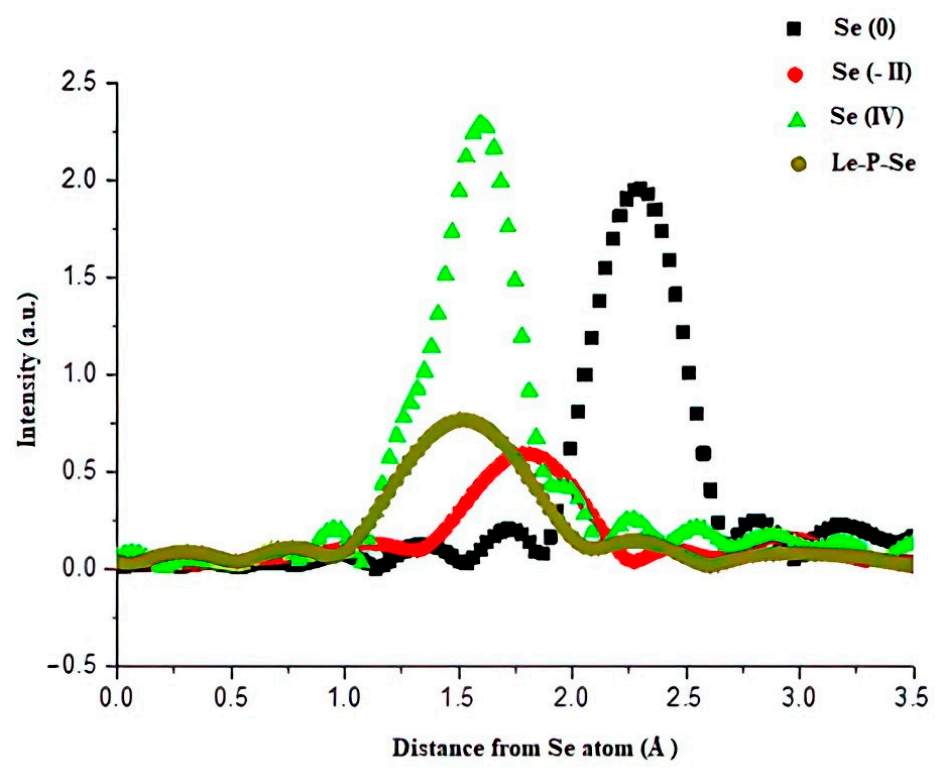

Figure 10. The EXAFS functions $\chi(\mathrm{R})$ of the sample studied and the reference materials. Se 0 - elemental red selenium powder as reference for Se (0) samples, Se (-II)-selenomethionine reference compounds for organically bound Se (-II), Se-IV-sodium selenite $\left(\mathrm{Na}_{2} \mathrm{SeO}_{3}\right.$ as reference for Se (IV)), Le-P-Se-Seexopolysaccharide fraction. 
In the tested sample, we observed only one distinct maximum at a distance of $1.5 \AA$ from the absorbing atom. In the selenomethionine reference sample (Se-II), the closest neighbors are two carbon atoms at a distance of about $1.9 \AA$, while in the sample of sodium selenite (Se IV), the closest three oxygen atoms are at a distance of about $1.3 \AA$ and the next two are at $1.6 \AA$. The remaining lower maxima are caused by a finite number of measurement points (quantization noise). Taking into account the intensity of the maximum corresponding to the nearest selenium neighborhood in sample Le-P-Se compared to the intensity of the nearest neighbor lines in sodium selenite equals 3 and the fact that the EXAFS signal is stronger in the case of a more rigid network (sodium selenite), it is possible to estimate the number of nearest oxygen neighbors in sample Le-P-Se as 2.

\subsection{Biological Activity of Se-Exopolysaccharides and Reference Fractions}

\subsubsection{The Effects of Exopolysaccharides on HUVEC and HeLa Cells Viability}

The results of the MTT test (3-(4,5-dimethylthiazol-2-yl)-2,5-diphenyl tetrazolium bromide test) showed that the cytotoxic activity of selenated (Le-P-Se) and non selenated (Le-P-0) exopolysaccharides isolated from the L. edodes culture medium differed markedly. The results are presented in Figure 12. The analysis of the graphs of the viability of HUVEC and HeLa cells incubated with exopolysaccharides showed that the Se-enriched exopolysaccharide Le-P-Se notably prolonged the cell survival time of normal HUVEC cells. The HUVEC cells viability after $24 \mathrm{~h}$ was enhanced by $54 \%$, while after $48 \mathrm{~h}$, the value increased to $138 \%$. This effect was not observed for malignant HeLa cells: the viability of the HeLa cells does not significantly change in the presence of both exopolysaccharide fractions, and was even slightly decreased. Interestingly, the reference (not selenated) fraction did not increase the survival rate of HUVEC cells, but even reduced it by $29-47 \%$.

\subsubsection{Protective Effect on Exogenous Oxidative Stress}

We tested the protective effect of fractions Le-P-Se and Le-P-0 against oxidative stress in cells incubated with hydrogen peroxide. The results showed that Se-enrichment significantly increased the antioxidant effect of exopolysaccharides isolated from the L. edodes culture medium (Figure 13). Cell viability in the presence of Se-exopolysaccharide was $12-13 \%$ higher as compared to non-selenated exopolysaccharide. When compared to the control (cells treated with hydrogen peroxide at a concentration of $100 \mu \mathrm{M}$ ), the presence of Se-exopolysaccharide increased cell viability by $30 \%$. In turn, when compared to the control cells treated with hydrogen peroxide at a concentration of $300 \mu \mathrm{M}$, the increase of cell viability was much higher, reaching $47 \%$.

\subsubsection{Granulocytes Separation and the Effects of Exopolysaccharides on Superoxide} Production by Granulocytes

In our previous studies, the influence of all polysaccharides on the production of reactive oxygen species by human granulocytes at concentrations of $1 \mu \mathrm{g} / \mathrm{mL}, 10 \mu \mathrm{g} / \mathrm{mL}$, and even at a high concentration of $100 \mu \mathrm{g} / \mathrm{mL}$ was not observed [25]. Therefore, in the present report, we checked the effect of exopolysaccharide Le-P-Se and Le-P-0 on the production of reactive oxygen species by these cells (Figure 11), but only at a high concentration of $100 \mu \mathrm{g} / \mathrm{mL}$. The analysis of the concentration of $\mathrm{nmol} \mathrm{O}_{2}$ in the granulocyte supernatants showed that Le-P-Se and Le-P-0 had no significant effect on the production of reactive oxygen species by these cells (Figure 11). Therefore, it is unfounded to study this effect at lower concentrations.

2.10.4. Comparison of the Effects of Se-Exopolysaccharides on the Proliferation of Human Peripheral Blood Mononuclear Cells (PMBCs)

Both exopolysaccharide fractions Le-P-Se and Le-P-0 tended to reduce PMBC proliferation induced by anti-CD3 $\mathrm{mAb}(\mathrm{OKT} 3)$. The reduction in the number of proliferating $\mathrm{T}$ cells, as compared to the control culture, was significant $(p<0.05)$ at the polysaccharide concentrations of 10 and $100 \mu \mathrm{g} / \mathrm{mL}$. The antiproliferative activity of the Se-enriched fraction was higher than that of the reference fraction, particularly at the concentration of 
$10 \mu \mathrm{g} / \mathrm{mL}$ (29\% vs.14\%, Figure 14$)$. At the concentration of $100 \mu \mathrm{g} / \mathrm{mL}$, the difference in the antiproliferative activity of Le-P-Se and Le-P-0 fractions was lower at $46 \%$ versus $41 \%$.

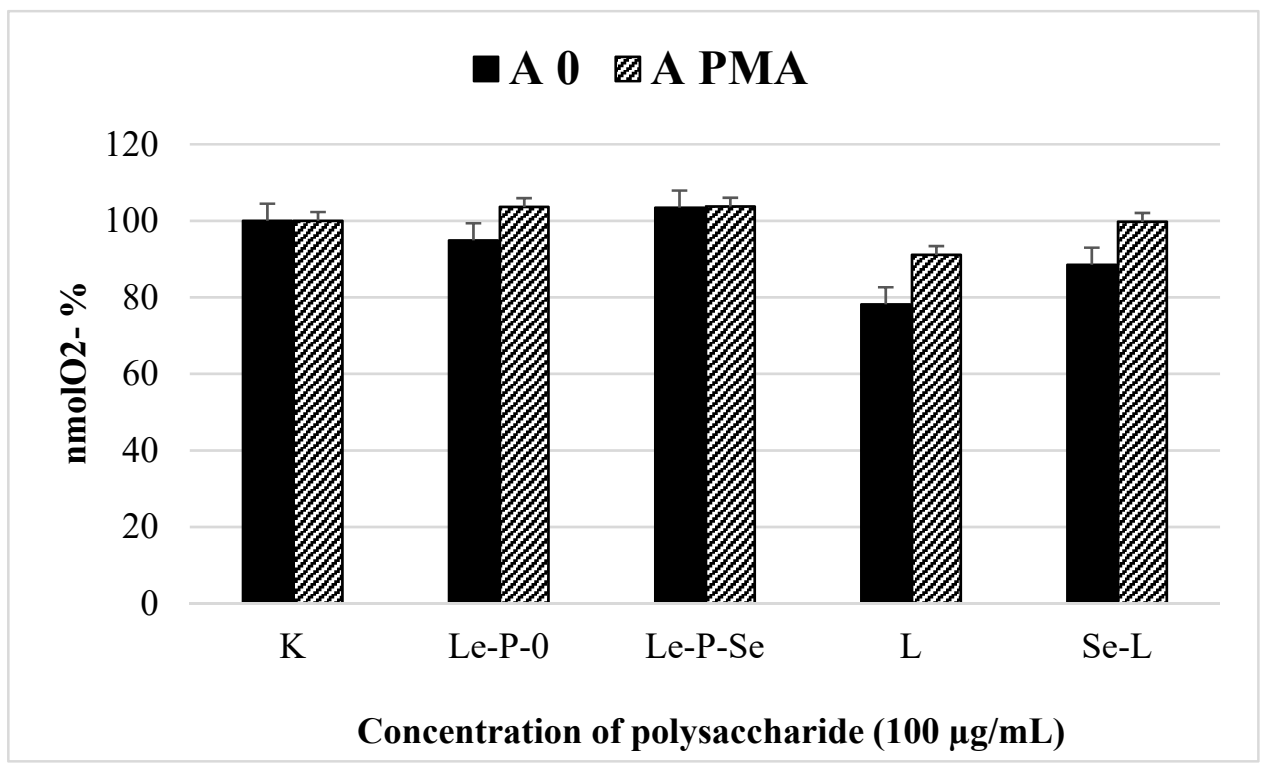

Figure 11. Comparison of the effects of the exopolysaccharide fractions isolated from the culture medium (selenated-Le-P-Se and not selenated Le-P-0) and polysaccharides extracted from the mycelial biomass (selenated-Se-L and not selenated L) [25] on the production of superoxide anions (nmols $\mathrm{O}_{2}{ }^{-}$). The phorbol 12-myristate 13-acetate ( $\left.\mathrm{APMA}_{\mathrm{PMA}}\right)$ and the auto- $\left(\mathrm{A}_{0}\right)$ and stimulation of granulocytes was expressed as a level of nmols $\mathrm{O}_{2}{ }^{-}$, as determined by measurement of cytochrome $\mathrm{c}$ reduction rate.

In all other tests, with non-stimulated PBMCs (autostimulation), stimulation with phytohemagglutinin (PHA) and by use of a suspension of Staphylococcus aureus Cowan strain (SAC), no effect on PBMCs proliferation was observed.

\section{Discussion}

The results of numerous studies on the effects of selenium incorporation into polysaccharides have indicated a significant increase in their biological activity, particularly immunomodulating, anti-cancer, and antioxidant effects [18]. In our previous study on the activity of water-soluble Se-polysaccharides isolated from the L. edodes mycelium, we also observed significant activity enhancement related to the incorporation of selenium [25].

Since exopolysaccharides secreted by mycelial cultures to the culture medium often show strong biological activity and, at the same time, significantly differ in structure from the polysaccharides extractable from the fungal mycelium [33,57], in the current research we undertook structural and activity studies of the Se-exopolysaccharides produced by L. edodes. Our first aim was to obtain novel, biologically active seleno-exopolysaccharides with defined structures, while the second aim, no less important, to compare the structural features of Se-exopolysaccharides secreted into the culture medium with previously studied Se-polysaccharides isolated from the mycelium of the same species of fungus $[24,25,58]$. Numerous researchers have found that the same species of fungus, depending on the strain and growing conditions (e.g., the composition of the medium), may secrete into the medium exopolysaccharides of different structures or in different amounts [59]. Therefore, we tested Se-exopolysaccharides isolated from the post-culture medium of the same L. edodes strain, grown under the same conditions and in the same medium as in our previous research. Thus, we were able to reliably compare the structure and activity of Se-exopolysaccharides with Se-polysaccharides isolated from mycelium. We found that supplementing L. edodes culture with $\mathrm{Na}_{2} \mathrm{SeO}_{3}$ in relatively high concentration $(30 \mu \mathrm{g} \mathrm{Se} / \mathrm{mL})$ [24] resulted in an increase in the production of exopolysaccharides. This outcome was probably caused by the 
high toxicity of $\mathrm{Na}_{2} \mathrm{SeO}_{3}$, which causes oxidative stress and induces the formation of free radicals. In response to oxidative stress, cells may synthesize non-enzymatic neutralizing metabolites [60]. It can be concluded that EPS may be such a compound [61].

For the purification of the exopolysaccharide fractions, precipitated from the postculture media, we chose the Yap and Ng method [43]. We have previously used the same method for the purification of the L. edodes cell wall Se-polysaccharides [24]. In this method, unlike methods based on the selective precipitation of polysaccharide fractions using strong bases and acids [62], we found no significant losses of selenium: nearly $50 \%$, vs. over $80 \%$ when we used the Chihara method (data not yet published). However, in order to overcome the loss of selenium during isolation, the culture was carried out in a medium containing selenium at the relatively high concentration of $30 \mu \mathrm{g} / \mathrm{mL}$. The selenium content in the crude Se-EPS fraction was $582.4 \mu \mathrm{g} / \mathrm{g}$, whereas $219.05 \mu \mathrm{g} / \mathrm{g}$ was found in the fraction Le-P-Se purified by the Yap and $\mathrm{Ng}$ method [43]. This result indicates the possibility of binding Se to exopolysaccharides in a stable manner, embedding itself in their structure [63]. The selenium content in the Se-exopolysaccharide fraction was slightly higher than in the isolates from the L. edodes Se-enriched mycelium $(190.8 \mu \mathrm{g} / \mathrm{g})$ [24].

The successive removal of the protein was performed using the Sevage method [64], which was used before the precipitation of the polysaccharides with alcohol. This process significantly reduced the protein content in the isolated polysaccharide fractions; however, about $15 \%$ of the protein component remained in them. The protein component is probably related to the structure of isolated polysaccharides, which are mainly mannans. The formation of connections with proteins is a common phenomenon among fungal polysaccharides [65]. Mannoproteins constitute the outer layer of the fungal cell wall, quite loosely related to its structure; the presence of these compounds in the culture medium is therefore very likely $[66,67]$.

There were no significant differences in the monosaccharide composition of Le-PSe and the reference samples. RP HPLC analysis confirmed that mannose is the basic component of the exopolysaccharides. In turn, in our previous work, we confirmed that glucose was the basic monosaccharide of the extractable mycelial Se-polysaccharides [24]. These results are consistent with the general pattern of fungal cell wall structure. The outer layer, which is gradually released into the environment, is made up of mannans, while the layers located near the plasmolemma contain glucans [68]. In addition to the main components of the exopolysaccharide fraction, i.e., mannose, glucose, and galactose, the monosaccharide composition of L. edodes exopolysaccharides is made up of six other types of subunits (Figure 6). This finding suggests that the exopolysaccharide fraction probably also includes complex heteroglycans, which is consistent with literature reports [69]. Uronic acids were found in both fractions, which have a key influence on the antioxidant activity of polysaccharides [70]. Analysis of the polysaccharide structure by IR spectroscopy confirms the results of the RP HPLC analysis of the polysaccharide structure. The IR spectra of the tested fractions (Le-P-Se and Le-P-0) confirmed the presence of mainly $\alpha$-, but also $\beta$-, glycans. Bands characteristic of amido groups indicated the presence of protein components. The structure of the main component of the Se-exopolysaccharide fraction was identified on the grounds of NMR COSY, TOCSY, NOESY, HSQC, and HMBC experiments as a highly branched $\alpha$-mannan. Its structure is similar to the structure of branched mannans of fungal origin, including yeast, described in the literature [71]. In 2010, Komura et al. hypothesized that the branched $\alpha$-mannans found in exopolysaccharide fractions of higher fungi originate from the culture medium, often containing yeast extract [66]. However, in the case of mannans isolated by us from submerged cultures of L. edodes, this hypothesis does not apply: the yeast mannans described by Komura, present in yeast extracts, have quite low molar masses, compared to our isolates, i.e., about $6.1 \times 10^{4} \mathrm{Da}$. The mannans isolated in our research are characterized by masses of $4 \times 10^{6} \mathrm{Da}$, i.e., many times higher.

We found a significant difference between the currently obtained Se-exopolysaccharides and the Se-polysaccharides previously isolated by us from the mycelium of L. edodes: these 
fractions also contained nearly $16 \%$ of $\alpha$-mannans, but the main components were $\alpha$ and $\beta$ glucans with dominant 1,4- $\alpha-, 1,6-\beta-$-, and 1,3- $\beta$-glycosidic bonds [24].

Another interesting, but still poorly studied, problem is the selenium bonding to the structure of polysaccharides. When the chemical methods are used to enrich natural polysaccharides with selenium, the degree of oxidation of selenium and its bonding ability in Se-polysaccharides are easy to predict [18]. On the other hand, when using biotechnological methods for obtaining the Se-polysaccharides, these important structural features are practically unpredictable and impossible to reliably determine by simple spectral analysis methods (IR, UV, ${ }^{13} \mathrm{C}$ and ${ }^{1} \mathrm{H}$ NMR, etc.) $[57,66]$. Thus, one of the important questions that we wanted to answer in the current research was whether the degree of oxidation and the chemical environment of selenium in Se-exopolysaccharides and the mycelial selenopolysaccharides isolated in previous studies are the same. For this purpose, we used, as in previous studies, the XAS (X-ray absorption spectroscopy) method.

To determine the type of interaction between selenium and EPS, the oxidation state of Se was determined and the structure of the distribution of atoms near the selenium atom was verified by X-ray absorption spectroscopy (XAS). The analysis of the spectrum in the X-ray absorption near-edge structure (XANES) showed that in the Le-P-Se sample the absorption energy was close to the Se IV reference sample, but with a difference of $0.8 \mathrm{eV}$. The average oxidation state in this sample therefore is slightly lower than IV. The exact degree of selenium oxidation cannot be determined due to the different nature of the binding in the Le-P-Se sample than in the Se-II reference sample, as evidenced by the presence of a strong "white line" (Figure 9). The extended X-ray absorption fine structure (EXAFS) simulation analysis showed that the distance to the nearest neighbor is lower than in the case of the mycelium Se-polysaccharides described in our previous publication (fractions Se-L and Se-S) [24]. In those fractions, selenium was clearly bound to two carbon atoms, probably by a glycosidic bond or in the selenopyranose ring [25,30]. In contrast, selenium in the currently examined Se-exopolysaccharide fraction occurs mainly at the fourth oxidation state, but also, similarly to the mycelial polysaccharide fractions, in the second degree.

The distance for the Le-P-Se sample is similar to the distance of the closest neighbor in the Se IV reference sample where the closest neighbor is oxygen. For the Le-P-Se sample, the spectrum showed only the signal from the closest neighbors, which revealed a large diversity of selenium surroundings (distances of further neighbors) in this sample, causing the signal to fade away from further coordination zones. In summary, in the compounds formed by selenium in this sample, only one closest coordination zone is present, and in it, on average, are located approximately two oxygen atoms. Further atoms are lighter or are at different distances, which causes the mutual extinction of the photoelectron waves reflected from these atoms.

It is a great challenge to propose a selenopolysaccharide (selenomannose) structure that meets these conditions, so the problem requires further intensive research including molecular modeling. Based on the above data, however, it can be concluded that apart from the mechanism of glycosidically incorporated selenium into the structure of polysaccharides, there are also other interactions between selenites and the structure of exopolysaccharides, resulting in stable selenium derivatives in the IV oxidation state. Based on the available data, we hypothesized that selenium was present in the Se-ester moiety, although it requires confirmation by appropriate studies. Interestingly, selenium in the IV oxidation state was not present in the structure of Se-polysaccharides previously isolated from the mycelial cell wall [24].

A summary of the significant differences in the primary structure, selenium oxidation state and selenium binding between Se-exopolysaccharides secreted into the culture medium and Se-polysaccharides extracted from the mycelium of L. edodes $[24,25,58]$ is presented in Table 3. 
Table 3. Structural differences between the Se-exopolysaccharides secreted into the culture medium and Se-polysaccharides extracted with hot water from the mycelium of L.edodes.

\begin{tabular}{|c|c|c|}
\hline Characteristic Feature & $\begin{array}{l}\text { Cell Wall Se-Polysaccharides } \\
\qquad[24,25,58]\end{array}$ & $\begin{array}{l}\text { Culture Medium } \\
\text { Se-Exopolysaccharides }\end{array}$ \\
\hline Protein content & $8-10 \%$ & $15-18 \%$ \\
\hline $\begin{array}{l}\text { Monosaccharide composition } \\
\text { (main components) }\end{array}$ & $\begin{array}{l}82 \% \text { Glucose } \\
13 \% \text { Mannose }\end{array}$ & $\begin{array}{l}89 \% \text { Mannose } \\
5 \% \text { Glucose }\end{array}$ \\
\hline $\begin{array}{l}\text { First order structure of main } \\
\text { components }\end{array}$ & $\begin{array}{l}\text { Linear 1,4- } \alpha \text {-glucans, linear } \\
1,3 \text { - } \beta \text { - and } 1,6 \text { - } \beta \text {-glucans and } \\
1,3-\beta \text {-branched } 1,6 \text { - } \beta \text {-glucans }\end{array}$ & $\begin{array}{l}\text { Highly 1,2- } \alpha \text {-branched } \\
1,4-\alpha \text {-mannans }\end{array}$ \\
\hline Selenium content & $190 \mu \mathrm{g} / \mathrm{g}$ & $219 \mu \mathrm{g} / \mathrm{g}$ \\
\hline Type of selenium binding & $\begin{array}{l}\text { Se-glycosidic bound, most } \\
\text { likely in } 1,4-\alpha \text { - or } \\
1,3-\beta \text {-Se-glycosides, or in the } \\
\text { Se-pyranose ring }\end{array}$ & $\begin{array}{l}\text { Most likely in Se-ester bound: } \\
\qquad-\mathrm{Se}=\mathrm{O}(\mathrm{OH})\end{array}$ \\
\hline Main Se-oxidation state & II & IV \\
\hline Molecular weight (approx.) & $3630 \mathrm{kDa}$ & $4468 \mathrm{kDa}$ \\
\hline
\end{tabular}

In our previous research, we found that the mycelial L. edodes extracts containing Se-polysaccharides showed weak cytotoxic activity in malignant HeLa cells, while strongly increasing $\mathrm{HMEC}_{1}$ normal cell viability [72]. Following this, we examined whether these effects were caused by the Se-polysaccharides content [25]. The results showed that both selenated and non-selenated polysaccharides isolated from L. edodes mycelium did not adversely affect cell viability [25]. Therefore, we found that selenium compounds other than the Se-polysaccharides were responsible for the previously found cytotoxic activity of L. edodes mycelial extracts. The Se-polysaccharide fractions, in turn, were responsible for the previously found opposite effect: a strong increase in cell viability, as determined by the MTT test in human umbilical vein endothelial (HUVECs) and human cervix carcinoma (HeLa) cells. Importantly, this effect was significantly higher (as much as 7-times) for normal cells rather than cancer cells [25]. A similar effect was found for the currently studied Se-exopolysaccharides, but their activity was much weaker. The increase in the survival of normal cells in the MTT test caused by the Se-exopolysaccharides was close to $50 \%$ (compared to nearly $90 \%$ for selenated mycelial fractions) [25]. The reference fraction showed no such activity, exhibiting even a slight reduction of the viability of the cells. Importantly, Se-exopolysaccharides in contrast to mycelial Se-polysaccharides [25] did not increase the survival of cancer cells (Figure 12A-D).

To summarize, there is a significant difference in the cytotoxic effect in the selected normal and cancer cell lines between the polysaccharide fraction isolated from L. edodes mycelium (which is a mixture of $\alpha$ - and $\beta$-glucans $[24,58]$ and branched $\alpha$-mannans isolated from the culture medium. In the first case, there was a tendency to increase the viability of the cells, especially of normal ones, in the second, there was a very weak cytotoxic effect. In both cases, the incorporation of selenium into the polysaccharide molecule significantly increases the viability of normal cells, with less (or no) impact on neoplastic cells. The differences are shown in Figure 12, comparing the activity of the currently obtained Seexopolysaccharides with the previously obtained Se-polysaccharides isolated from the mycelium of L. edodes. 
$\mathbf{A}$

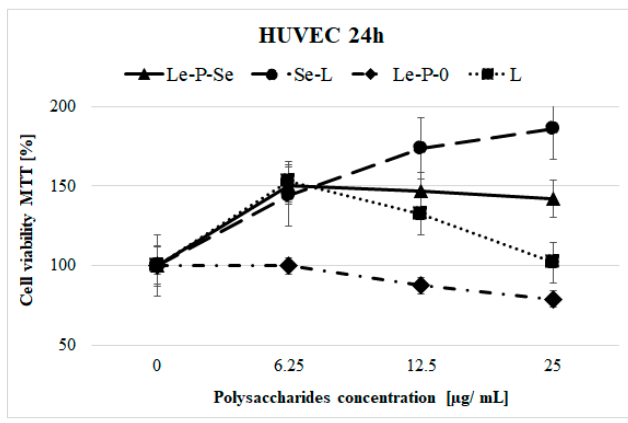

C

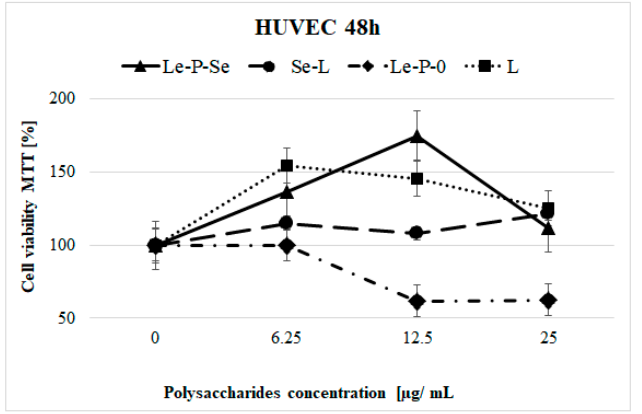

B

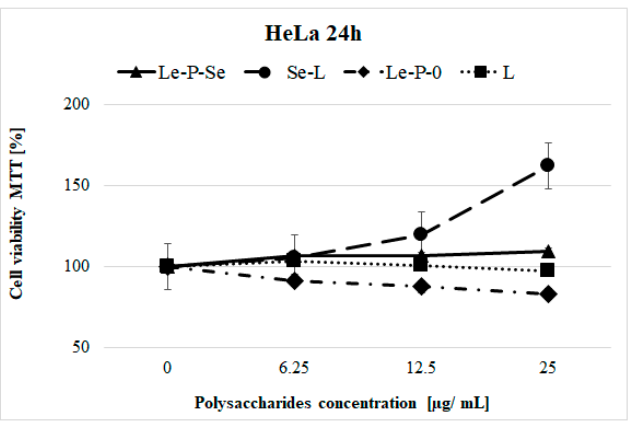

D

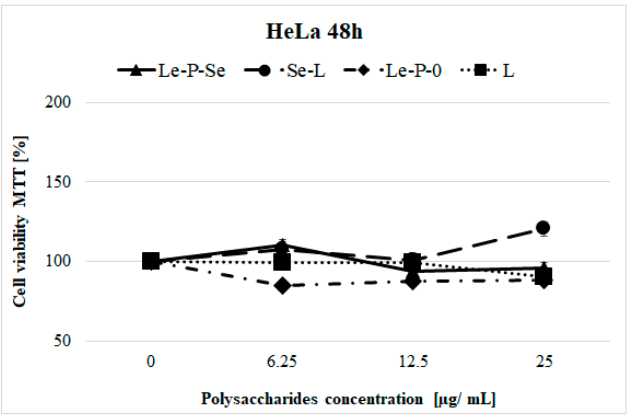

Figure 12. Comparison of the effects of the exopolysaccharide fractions isolated from the culture medium (selenated-Le-P-Se and not selenated Le-P-0) and polysaccharides extracted from the mycelial biomass (selenated-Se-L and not selenated L) [25] on HUVEC and HeLa cells viability. (A) HUVEC cells after $24 \mathrm{~h}$ of incubation. (B) HeLa cells after $24 \mathrm{~h}$ of incubation. (C) HUVEC cells after $48 \mathrm{~h}$ of incubation. (D) HeLa cells after $48 \mathrm{~h}$ of incubation. The viability of tested cells without added polysaccharide fractions was taken as $100 \%$. The error bars correspond to the standard deviation.

We found that the Se-exopolysaccharide fraction isolated from the culture medium showed a protective effect on exogenous oxidative stress. Both the Se-exopolysaccharide and the reference fraction displayed antioxidant activity: cell viability in the presence of the selenated exopolysaccharide was higher as compared to the non-selenated fraction and significantly (over two-times) higher as compared to the control, e.g., $\mathrm{H}_{2} \mathrm{O}_{2}-$ treated cells (Figure 13). As for the polysaccharide fractions isolated from the L. edodes mycelium [25], the effect was more evident for cells exposed to $300 \mu \mathrm{M} \mathrm{H}_{2} \mathrm{O}_{2}$. However, the Se-exopolysaccharide fraction (Le-P-Se) expressed much lower activity than the Sepolysaccharide fraction isolated from L. edodes mycelium (two times vs. six times enhanced cell viability) (Figure 13). The difference in the potency was not evident; however, for the non-selenium enriched fractions: a mixture of $\alpha$ - and $\beta$-glucans (L) previously isolated from mycelium and $\alpha$-mannan (Le-P-0) currently isolated from the culture medium showed similar protective effects against oxidative stress in both tests (Figure 13). There was, however, a significant difference in activity of the selenium-containing polysaccharide fractions isolated from mycelium and from the culture medium (Se-L and Le-P-Se) (Figure 13).

The concentration of selenium in the Se-exopolysaccharide (Le-P-Se) and the previously obtained Se-polysaccharide fraction isolated from mycelium (Se-L) is similar to, or even higher, than that of Le-P-Se (219 vs $191 \mu \mathrm{g} / \mathrm{g})$. The significant difference in antioxidant activity between selenium-enriched fractions could therefore be related to the differences in the selenium oxidation degree (II in Se-L and IV in Le-P-Se) and a different binding mode of selenium in the structure of polysaccharides. 


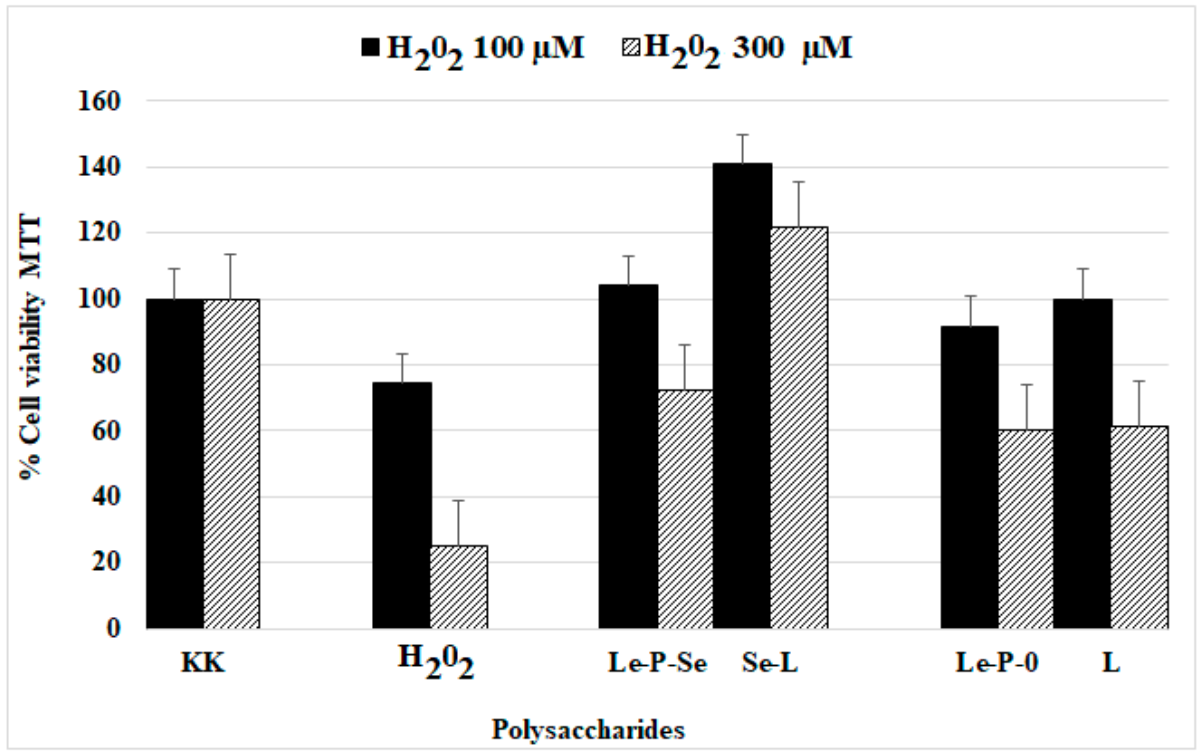

Figure 13. Comparison of the protective effect of exopolysaccharides isolated from the culture medium (selenated fraction Le-P-Se and non-selenated fraction Le-P-0) and polysaccharides extracted from the mycelial biomass (selenated-Se-L and not selenated L) [25] on exogenous oxidative stress induced by hydrogen peroxide in concentrations of 100 and $300 \mu \mathrm{M}$. KK-control; $\mathrm{H}_{2} \mathrm{O}_{2}-\mathrm{control}$ cells $\mathrm{H}_{2} \mathrm{O}_{2}$ treated. The data represent the mean \pm S.D of 4 observations.

As for the immunomodulatory activity of the tested exopolysaccharide fractions, similarly to the fractions isolated from mycelium, no immunostimulatory activity was found. None of the polysaccharides had a significant effect on the reactive oxygen species generation by granulocytes (Figure 11). However, in tests of the effects of the Se-enriched and reference exopolysaccharide fractions on the proliferation of human PBMCs, similar activity was found as observed for the previously tested mycelial selenopolysaccharides. We observed that both fractions Le-P-Se and Le-P-0 significantly inhibited proliferation of the T lymphocytes induced by anti-CD3 mAb (OKT3), but not by phytohemagglutinin (PHA). Both mitogens are used to evaluate the $\mathrm{T}$ proliferative response; however, they use different mechanisms to promote $\mathrm{T}$ cell effector functions. As we mentioned in our previous work [25], PHA stimulates $\mathrm{T}$ cell proliferation by interactions with the $\mathrm{N}$-acetylgalactosamine glycoprotein present on these cells [73]. OKT3 stimulates T cells via CD3-mediated signaling [74]. To summarize, we found that both exopolysaccharide samples, Le-P-Se and Le-P-0, in concentrations of 10 and $100 \mu \mathrm{g} / \mathrm{mL}$, significantly inhibited proliferation of the T lymphocytes stimulated by OKT3, which suggests their potential effects on the T cell receptor (TCR)/CD3 pathway. This issue warrants further investigations. Notably, the inhibition of $\mathrm{T}$ cell proliferation by the exopolysaccharide fractions was distinctly weaker than the effect with the mycelial Se-polysaccharides examined in our previous work ( $50 \%$ vs. $89 \%$ of inhibition) [25]. For both exopolysaccharide fractions, Le-P-Se and Le-P-0, no inhibitory effect of polysaccharide fractions on SAC-stimulated PBMC proliferation was observed. This outcome suggested that, similarly to previously tested mycelial fractions Se-L and L [25], currently tested Se-exopolysaccharide fractions may act as selectively immunosuppressive compounds. The effect of Se-exopolysaccharide was significantly stronger than that of the reference fraction, but much weaker than that of Se-polysaccharide isolated from mycelium. The Se-exopolysaccharide was also much more selective: it only affected the proliferation of $\mathrm{T}$ lymphocytes and was only active in the test suggesting activity through TCR/CD3. The comparison of the activity of Sepolysaccharides isolated from the culture medium and from mycelium of L. edodes (Le-P-Se and Se-L) and non-selenated reference fractions (Le-P-0 and L) is presented in Figure 14. 
$\mathbf{A}$

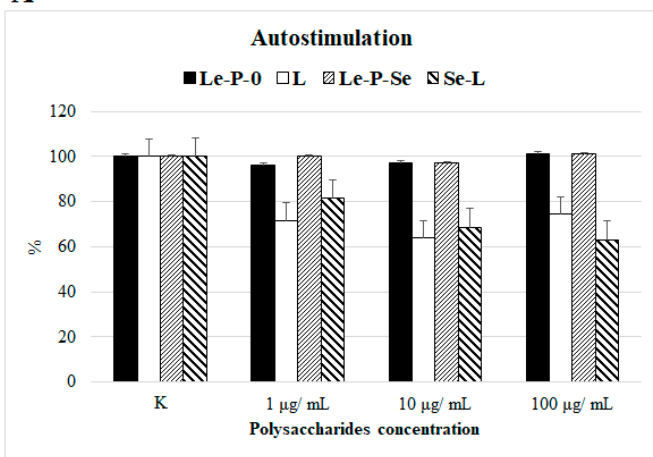

C

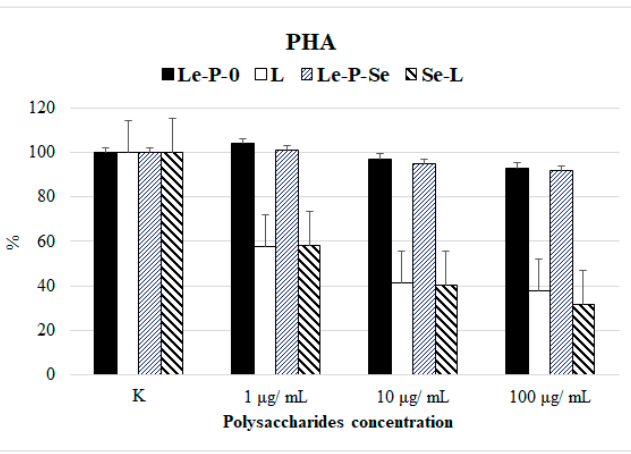

B

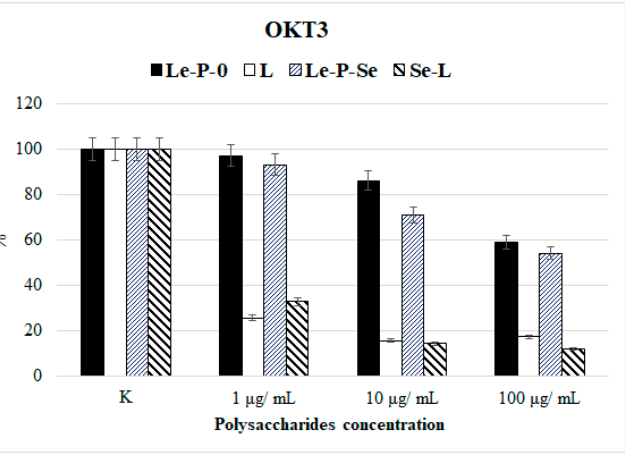

D

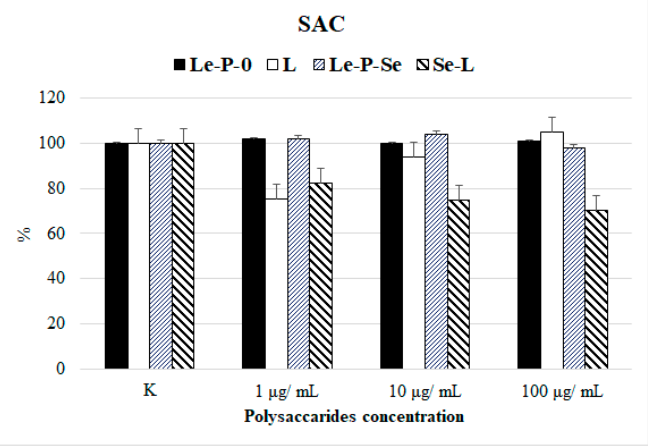

Figure 14. Comparison of the effects of exopolysaccharides isolated from the culture medium (Le-P-Se, Le-P-0) and polysaccharides extracted from the mycelial biomass (selenated-Se-L and not selenated L) [25] on proliferation of peripheral blood mononuclear cells (PBMCs). (A) Nonstimulated (autostimulation) and stimulated with: (B) Anti-CD3 monoclonal antibody (OKT3); (C) Phytohemagglutinin (PHA); and (D) Suspension of Staphylococcus aureus Cowan strain (SAC). The results are presented as the percentage of proliferation in control cultures (without polysaccharides). The error bars correspond to the standard deviation.

\section{Conclusions}

Summarizing the Research Results

We found that the Se-exopolysaccharide fraction secreted into the culture medium by L. edodes mycelial cultures consists mainly of highly branched $\alpha$-mannans of a structure similar to the polysaccharides found in yeast and several higher fungi, but characterized by significantly higher molecular weight. Selenium in the Se-exopolysaccharide fraction was bound to the structure of polysaccharides in a different way than seen in the Sepolysaccharides extracted from L. edodes mycelium and showed the oxidation state IV. The isolated Se-mannans show basically similar biological activity to the selenium-enriched fractions previously isolated from the L. edodes mycelium, which were mainly $\alpha$-and $\beta$-glucans, but also contained the $\alpha$-mannan moiety. The effect of Se-exopolysaccharides, in the cytotoxicity (MTT) test, included selective enhancement of the survival of normal cells, with no effect on cancer cells. The Se-polysaccharides isolated from mycelium, in turn, showed much stronger, but non-selective effects in this test. The isolated Se-exopolysaccharide showed high antioxidant activity, significantly higher than that of the reference fraction, but much lower than that for the Se-polysaccharide fraction isolated from mycelium. The Se-exopolysaccharide showed a similar inhibitory effect on the proliferation of Tlymphocytes as observed for the previously tested mycelial Se-polysaccharide, but only in the OKT3 test, without the simultaneous effect on B lymphocytes. The effect was much weaker than that for the fraction isolated from mycelium, although more selective. The differences between the activity of the seleno-exopolysaccharides and selenopolysaccharide fractions isolated from the mycelium were probably to a significant extent due to the difference in selenium binding and its degree of oxidation. Both the structure and the mechanism of the 
potential immunosuppressive effect of the studied Se-exopolysaccharides, composed of selenium-containing highly branched $\alpha$-mannans with a $15 \%$ protein component, require further detailed studies.

Here we summarize the main findings presented in the current paper, and point out the main differences in the structure and biological activity of the Se-exopolysaccharides secreted into the culture medium by L. edodes mycelia and Se-polysaccharides isolated from the $L$. edodes mycelial cell wall (described in our previous research) $[24,25,58]$. We have shown that, unlike linear Se-1,4- $\alpha$-D-glucans, Se-1,3- $\beta$-D-glucans, Se-1,6- $\beta$-D-glucans and branched $1,3-\beta-1,6-\beta$-D-glucans isolated from the mycelial cell wall, the Se-exopolysaccharides secreted into the medium are highly branched Se-1,2- $\alpha-1,4-\alpha$-mannans.

- In contrast to the cell-wall Se-polysaccharides (Se-glycosides or selenopyranosederivatives, with selenium in the -II oxidation state), selenium was bound to Seexopolysaccharides most likely by ester bonds, remaining in the IV oxidation state. Interestingly, this oxidation state was absent in cell wall Se-polysaccharides.

- We have also shown a significant effect of the different polysaccharide structures and degrees of selenium oxidation on the immunomodulating, cytotoxic, and antioxidant properties of Se-polysaccharides. However, this activity was not completely different or the opposite to previously described, while mannans are in general present in the outer layers of the cell wall. They are secreted into the culture medium, but also remain in small amounts in cell wall isolates.

Due to the potential use of the Se-polysaccharides derived from L. edodes as novel immunosuppressive drugs in transplantology and autoimmune diseases, we plan to conduct advanced research on the mechanisms of action and pharmacokinetic properties (ADME Tox studies) of these compounds.

\section{Materials and Methods}

\subsection{Microorganism and Cultivation Media}

The L. edodes (Berk.) Pegler strain used in this study was American Type Culture Collection (ATCC) 48085. Se-Exopolysaccharide fractions (Se-EPS), hereafter referred to as Le-P-Se, were isolated from the post-culture liquid medium, in which the submerged culture of this fungus was carried out. The mycelial cultures were grown under the conditions described in our previous reports $[24,75,76]$. To specify, the mycelial cultures were cultivated under submerged conditions in a $10 \mathrm{~L}$ fermenter (BioTec FL 110, Stockholm, Sweden.). The culture media were fortified with selenium at a concentration of $30 \mu \mathrm{g} / \mathrm{mL}$, by the addition of sodium selenite $\left(\mathrm{Na}_{2} \mathrm{SeO}_{3}\right.$, Sigma, Cell Culture Tested). The initial $\mathrm{pH}$ of the medium was 6.5. The medium was inoculated with $5 \%(v / v)$ of seed culture and cultivated at $26^{\circ} \mathrm{C}$. Fermentation was performed for 10 days under the following conditions: aeration rate, $0.5 \mathrm{vvm}$ (volume per volume per minute); agitation speed, $200 \mathrm{rev} / \mathrm{min}$; and working volume, $8 \mathrm{~L}$. Mycelia were filtered off and the liquid post-culture medium was used for the isolation of the Se-exopolysaccharides. At the same time, the reference cultures were grown under the same conditions in media not enriched with selenium. The post-culture media were used for the isolation of reference exopolysaccharides (Le-P-0).

\subsection{Isolation and Purification of Se-Enriched and Reference Exopolysaccharide Fractions}

The Se-exopolysaccharide (Le-P-Se) and reference (Le-P-0) fractions were isolated from the Se-enriched and reference post culture liquid medium. The culture medium was concentrated to $20 \%$ with rotary evaporators (Buchi Rotavapor R-200). After cooling the concentrate to room temperature, the solution was deproteinized for $10 \mathrm{~min}$ by the Sevage method [64] with a mixture of chloroform and butanol (3:1 $\mathrm{v} / \mathrm{v})$. The deproteinization procedure was repeated 3 times. Then the exopolysaccharides were precipitated by adding one volume of $96 \%$ ethanol 1:1 and stored for 14 days at $4{ }^{\circ} \mathrm{C}$. The precipitate was centrifuged to separate the supernatant from the pellet $(10 \mathrm{~min}, 6800 \mathrm{rpm})$. The pellet was frozen in liquid nitrogen at $-195^{\circ} \mathrm{C}$ and subjected to lyophilization. The freeze-dried crude exopolysaccharide fractions were purified by use of the modified Yap and $\mathrm{Ng}$ method [43] described 
in our previous paper [24]. Namely, hot water $\left(60^{\circ} \mathrm{C}, 30\right.$ volumes $\left.(v / w)\right)$ was added to the freeze-dried pellet and homogenized for $1 \mathrm{~min}$. The homogenate was boiled for $10 \mathrm{~h}$ on a magnetic stirrer to obtain a clear solution. The hot solution was passed through a vacuum filter. After cooling the extract to room temperature, ethanol (1:1, one volume) was added and the mixture was stored for 14 days at $4{ }^{\circ} \mathrm{C}$. The centrifugation, freezing in liquid nitrogen, and freeze-drying steps were repeated to obtain purified exopolysaccharide in powder form.

\subsection{Structural Analysis of Exopolysaccharide Fractions \\ 5.3.1. IR Spectral Analysis}

IR spectra were recorded in the range $4000-700 \mathrm{~cm}^{-1}$ with a Fourier transform infrared (FTIR) spectrometer (Shimadzu, FTIR 8300). The test samples were prepared using the KBr-disk method [77].

5.3.2. Determination of the Molecular Weight by High Performance Gel Permeation Liquid Chromatography (HPGPC) with Light-Scattering Detection

The molecular weight and homogeneity of the polysaccharide fractions were determined by size exclusion chromatography (HPSEC) with light scattering (ELSD) detection according to the procedure reported by Cheong et al. (2015) [77], with modifications. The GPC system (Shimadzu) is equipped with two HPLC pumps (Shimadzu), the GPC TSKgel SuperMultipore PW-H column, $6.0 \mathrm{ID} \times 150 \mathrm{~mm}$, (TOSOH Bioscience), Guard SuperMP PW-H $4.6 \mathrm{~mm}$ ID $\times 35 \mathrm{~mm}$ (TOSOH Bioscience), column oven (Shimadzu) and evaporator lamp-scattering detector (ELSD LTII). Deionized water was used as the mobile phase. Column and detector temperatures were $40^{\circ} \mathrm{C}$ and $50{ }^{\circ} \mathrm{C}$, respectively, and the flow rate and injection volume were $0.4 \mathrm{~mL} / \mathrm{min}$ and $20 \mu \mathrm{L}$, respectively. The $\beta$-glucan standards (40 kDa, 123 kDa, 183 kDa, 245 kDa, 359 kDa, Megazyme, Ireland and 500 kDa, Boc Sciences, New York USA) and $\alpha$-glucan standards (401 kDa, 277 kDa, 196 kDa, 124 kDa, 43.5 kDa, $21.4 \mathrm{kDa}, 9.9 \mathrm{kDa}, 4.4 \mathrm{kDa}$, PSS Polymer Standards Service Gmbh) were used to plot a calibration curve. A calibration curve was plotted as the correlation between the retention time and the molecular weight $(\mathrm{Mp})$ of the standards.

5.3.3. Reversed Phase High Performance Liquid Chromatography (RP-HPLC) Determination of Se Content

The RP-HPLC procedure used was a modified fluorometric method of Se determination after derivatization with 2,3-diaminonaphthalene (4,5-benzopiazselenol formation) with fluorescence detection [78], as described in our previous papers $[63,75,76]$.

\subsubsection{Determination of Protein Content}

The results were obtained by the Bradford spectrophotometric method [79] and the nitrogen content and fractions analysis with the CHNS Vario EL III elemental analyzer (Elementar, Germany). Protein content was calculated using a conversion factor of 6.25 from total nitrogen to protein.

5.3.5. Reversed Phase High Performance Liquid Chromatography (RP-HPLC) Determination of the Amino Acid Composition of a Protein Component after Acid Hydrolysis

The derivatization of amino acids with the OPA reagent was performed. The amino acids in the dry matter of the polysaccharide hydrolysate were then determined by highperformance liquid chromatography. Hydrolysis was performed prior to analysis under acidic conditions with $6 \mathrm{M} \mathrm{HCl}$ at $110^{\circ} \mathrm{C}$ for $24 \mathrm{~h}$. The RP HPLC gradient method and the derivatization reaction conditions have been described in the previous work [75]. 
5.3.6. Reversed Phase High Performance Liquid Chromatography (RP-HPLC) Determination of Monosaccharide Composition

Monosaccharide composition of the polysaccharides was determined by a reversed phase high performance liquid chromatography (RP HPLC) method described in our previous paper [44]. Prior to the analysis, the exopolysaccharides were hydrolyzed for $5 \mathrm{~h}$ with $3 \mathrm{M}$ TFA at $120^{\circ} \mathrm{C}$.

\subsubsection{X-ray Absorption Spectroscopy (XAS)}

XAS measurements were carried out at beamline $X$ of the synchrotron laboratory HASYLAB DESY in Hamburg, Germany. The selenium K edge spectra were collected in fluorescence mode at the temperature of $10 \mathrm{~K}$ to reduce the influence of thermal disorder on the extended X-ray absorption fine structure (EXAFS) spectra. The following reference compounds were used: selenomethionine for organically bound Se (-II) (Aldrich), red selenium powder obtained by the reduction of selenites at the Department of Drug Technology and Pharmaceutical Biotechnology, Medical University of Warsaw for Se (0), sodium selenite $\left(\mathrm{Na}_{2} \mathrm{SeO}_{3}\right.$, Sigma, Cell Culture Tested, Sigma, Saint Louis, MO, United States)for Se (IV). For the X-ray absorption near-edge structure (XANES) analysis, the XAS experimental data were normalized to the edge step and the backgrounds were subtracted using the standard procedures in the ATHENA program. EXAFS simulations were carried out using FEFF 8.4 code.

\subsubsection{NMR Spectral Analysis}

The NMR spectra were obtained on a Bruker $600 \mathrm{MHz}$ Avance III spectrometer using a $5 \mathrm{~mm} \mathrm{QCI}{ }^{1} \mathrm{H} /{ }^{13} \mathrm{C} /{ }^{15} \mathrm{~N} /{ }^{31} \mathrm{P}$ probe equipped with a z-gradient. About $10 \mathrm{mg}$ of exopolysaccharides were dissolved in ${ }^{2} \mathrm{H}_{2} \mathrm{O}(99.96 \%, 0.6 \mathrm{~mL})$. The NMR spectra were recorded at $25^{\circ} \mathrm{C}$ using acetone $\left(\delta_{\mathrm{H}} 2.225, \delta_{\mathrm{C}} 31.05 \mathrm{ppm}\right)$ as an internal reference. The data were acquired and processed using Bruker Topspin software (version 3.1) and SPARKY (Goddard and Kneller, 2001). The signals were assigned using one and two homo- and heteronuclear experiments: COSY, TOCSY, NOESY, HSQC with and without carbon decoupling and HMBC. The TOCSY experiments were carried out with mixing times of 30, 60 and $90 \mathrm{ms,}$ NOESY with mixing times of $100 \mathrm{~ms}$ and $300 \mathrm{~ms}$, and HMBC with $60 \mathrm{~ms}$ mixing time.

\subsection{Biological Activity of Se-Exopolysaccharides and Reference Fractions}

5.4.1. The Effect of Exopolysaccharides on HUVEC and HeLa Cells Viability (MTT Assay)

The methodology was consistent with that previously described by Kaleta et al. [25]. Cell viability was determined by the MTT assay. The activities of the exopolysaccharides isolated from selenium-enriched medium (Le-P-Se) and from non-selenium medium (Le-P$0)$ were tested.

\subsubsection{Protective Effect on Exogenous Oxidative Stress}

The methodology was consistent with that previously described by Kaleta et al. [25]. The HeLa cells were incubated with Le-P-Se and Se-P-0 exopolysaccharide fractions at a concentration of $25 \mu \mathrm{g} / \mathrm{mL}$ for $30 \mathrm{~min} . \mathrm{H}_{2} \mathrm{O}_{2}$ at a concentration of $100 \mu \mathrm{M}$ or $300 \mu \mathrm{M}$ was then added to the cells for $24 \mathrm{~h}$.

5.4.3. Granulocyte Separation and the Effects of Exopolysaccharides on Superoxide Production by Granulocytes

Blood samples $(8 \mathrm{~mL})$ were collected from healthy blood donors. All blood samples were commercially obtained from the Regional Blood Centre in Warsaw. Isolation of granulocytes was performed by density gradient centrifugation on Histopaque-1077 and Histopaque-1119 (Sigma). Granulocytes were harvested from the interface between Histopaque-1077 and Histopaque-1119. Granulocytes $\left(2.5 \times 10^{5}\right.$ cells/well) were cultured in 96-well round-bottom microplates in the medium containing PBS, $6 \mathrm{mM}$ glucose (Sigma) and $1 \%$ bovine serum albumin (BSA, Biowest). Granulocytes were either activated or not 
by phorbol 12-myristate 13-acetate (PMA, Sigma) and incubated with cytochrome c (Sigma) and exopolysaccharides fractions at the concentration of $100 \mu \mathrm{g} / \mathrm{mL}$ for $30 \mathrm{~min}$ at $37^{\circ} \mathrm{C}$ and $5 \% \mathrm{CO}_{2}$ in a humidified incubator. Control cultures contained an equivalent amount of medium. Generation of $\mathrm{O}_{2}{ }^{-}$by reduction of cytochrome $\mathrm{c}$ was detected at room temperature using a microplate reader at $550 \mathrm{~nm}$ (Chromate 4300 Microplate Reader). Because cytochrome c may be reduced by other radical species, additional control experiments with superoxide dismutase (SOD, $30 \mathrm{mg} / \mathrm{mL}$, Sigma) were performed to confirm that the reduction was dependent on $\mathrm{O}_{2}{ }^{-}$. All experiments were performed in triplicates.

The study was approved by the Local Ethics Committee (no. KB/174/2017) and all subjects provided written informed consent. The procedures followed were in accordance with the Helsinki Declaration of 1975, as revised in 2000.

5.4.4. PBMC Separation and the Effects of Polysaccharides on Mitogen-Stimulated PBMC Proliferation

Blood samples $(8 \mathrm{~mL})$ were collected from healthy blood donors. Isolation of peripheral blood mononuclear cells (PBMCs) was performed by density gradient centrifugation on Histopaque-1077 (Sigma). All blood samples were commercially obtained from the Regional Blood Centre in Warsaw. The separated PBMCs were resuspended in RPMI 1640 medium (Gibco) containing $2 \mathrm{mM}$ L-glutamine (Sigma), antibiotic-antimycotic solution (1.5\% penicillin-streptomycin-amphotericin, Invitrogen) and $10 \%$ fetal bovine serum (FBS, Gibco). PBMCs $\left(1 \times 10^{6}\right.$ cells/well) were cultured in 96-well flat-bottom microplates. Cells were either not stimulated or stimulated with mitogens: anti-CD3 mAb (OKT3, $1 \mu \mathrm{g} / \mathrm{mL}$, BD Pharmingen), phytohemagglutinin (PHA, $20 \mu \mathrm{g} / \mathrm{mL}$, Sigma) and a suspension of Staphylococcus aureus Cowan strain (SAC, $0.004 \% w / v$, Calbiochem) and incubated with Le-P-Se or Le-P-0 exopolysaccharide fractions at concentrations of 1, 10 and $100 \mu \mathrm{g} / \mathrm{mL}$. PBMCs were cultured for $72 \mathrm{~h}$ at $37^{\circ} \mathrm{C}$ and $5 \% \mathrm{CO}_{2}$ in a humidified incubator. PBMC proliferation was assessed using $\left[{ }^{3} \mathrm{H}\right]$-thymidine $(1 \mu \mathrm{Ci} /$ well; $113 \mathrm{Ci} / \mathrm{nmol}, \mathrm{NEN})$ incorporation. After $18 \mathrm{~h}$ of culture, PBMCs were harvested and the radioactivity was measured with the scintillation beta-counter (Wallac, PerkinElmer). The amount of radioactivity incorporated into DNA of PBMCs was proportional to the number of proliferating cells. The readout was expressed as corrected count per minute (cсpm) per well. All experiments were performed in triplicates.

\subsection{Statistical Analysis}

The Mann-Whitney U-test and Spearman correlation were applied using Statistica 9.0 (StatSoft Inc, Tulusa, Ok, United States)Differences from control cultures were considered statistically significant at a $p$ value $<0.05$.

Author Contributions: Conceptualization, S.G.-J., J.T.; methodology, S.G.-J., M.K., J.T. (biotechnology), R.Z. and B.K. (immunology), A.G. and S.G. (spectral analysis), P.P. (molar mass determinations); T.S. and C.K. (XAS analysis), B.N., M.C. (cell lines experiments); validation, S.G., P.P., B.K., T.S., M.C.; formal analysis, J.T.; investigation, M.K., S.G.-J., S.G., B.K., P.P., T.S., M.C., J.K.-B.; resources, S.G.-J.; data curation, S.G.-J., B.K., M.K., S.G., R.Z., M.C., B.N.; writing—original draft preparation, S.G.-J., J.T., C.K., B.K.; writing—review and editing, S.G.-J., J.T., R.Z., B.K., S.G., M.C., B.N.; visualization, S.G.-J., S.G., P.P.; supervision, J.T.; project administration, S.G.-J., J.T.; funding acquisition, S.G.-J. All authors have read and agreed to the published version of the manuscript.

Funding: This work was supported by grant from the Polish National Science Centre, Poland (grant number UMO-2017/27/N/NZ7/02948).

Institutional Review Board Statement: Not applicable.

Informed Consent Statement: All participants provided written informed consent to participate in the study. The study was approved by the local ethics committee. The procedures were carried out in accordance with the Helsinki Declaration of 1975 as revised in 2000.

Data Availability Statement: The data presented in this study are available on request from the corresponding author and co-authors. 
Acknowledgments: We want to thank Anna Próba for her great commitment and help in parts of the experimental work.

Conflicts of Interest: The authors declare no conflict of interest.

\section{References}

1. Wang, Q.; Wang, F.; Xu, Z.; Ding, Z. Bioactive Mushroom Polysaccharides: A Review on Monosaccharide Composition, Biosynthesis and Regulation. Molecules 2017, 22, 955. [CrossRef]

2. Wu, L.; Sun, J.; Su, X.; Yu, Q.; Yu, Q.; Zhang, P. A Review about the Development of Fucoidan in Antitumor Activity: Progress and Challenges. Carbohydr. Polym. 2016, 154, 96-111. [CrossRef]

3. Wijesekara, I.; Pangestuti, R.; Kim, S.-K. Biological Activities and Potential Health Benefits of Sulfated Polysaccharides Derived from Marine Algae. Carbohydr. Polym. 2011, 84, 14-21. [CrossRef]

4. Ni, W.; Zhang, X.; Wang, B.; Chen, Y.; Han, H.; Fan, Y.; Zhou, Y.; Tai, G. Antitumor Activities and Immunomodulatory Effects of Ginseng Neutral Polysaccharides in Combination with 5-Fluorouracil. J. Med. Food 2010, 13, 270-277. [CrossRef]

5. Chen, F.; Huang, G. Preparation and Immunological Activity of Polysaccharides and Their Derivatives. Int. J. Biol. Macromol. 2018, 112, 211-216. [CrossRef] [PubMed]

6. Naqash, F.; Masoodi, F.A.; Rather, S.A.; Wani, S.M.; Gani, A. Emerging Concepts in the Nutraceutical and Functional Properties of Pectin-A Review. Carbohydr. Polym. 2017, 168, 227-239. [CrossRef] [PubMed]

7. Friedman, M. Mushroom Polysaccharides: Chemistry and Antiobesity, Antidiabetes, Anticancer, and Antibiotic Properties in Cells, Rodents, and Humans. Foods 2016, 5, 80. [CrossRef] [PubMed]

8. Moradali, M.-F.; Mostafavi, H.; Ghods, S.; Hedjaroude, G.-A. Immunomodulating and Anticancer Agents in the Realm of Macromycetes Fungi (Macrofungi). Int. Immunopharmacol. 2007, 7, 701-724. [CrossRef] [PubMed]

9. Hoffman, J.L.; McConnell, K.P. Periodate-Oxidized Adenosine Inhibits the Formation of Dimethylselenide and Trimethylselenonium Ion in Mice Treated with Selenite. Arch. Biochem. Biophys. 1987, 254, 534-540. [CrossRef]

10. Rayman, M.P. The Importance of Selenium to Human Health. Lancet 2000, 356, 233-241. [CrossRef]

11. Humann-Ziehank, E.; Wolf, P.; Renko, K.; Schomburg, L.; Ludwig Bruegmann, M.; Andreae, A.; Brauer, C.; Ganter, M. Ovine Pulmonary Adenocarcinoma as an Animal Model of Progressive Lung Cancer and the Impact of Nutritional Selenium Supply. J. Trace Elem. Med. Biol 2011, 25 (Suppl. S1), S30-S34. [CrossRef]

12. Brozmanová, J.; Mániková, D.; Vlčková, V.; Chovanec, M. Selenium: A Double-Edged Sword for Defense and Offence in Cancer. Arch. Toxicol. 2010, 84, 919-938. [CrossRef]

13. Rayman, M.P. Selenium in Cancer Prevention: A Review of the Evidence and Mechanism of Action. Proc. Nutr. Soc. 2005, 64, 527-542. [CrossRef]

14. Rayman, M.P. Food-Chain Selenium and Human Health: Emphasis on Intake. Br. J. Nutr. 2008, 100, 254-268. [CrossRef]

15. Rayman, M.P. Selenium and Human Health. Lancet 2012, 379, 1256-1268. [CrossRef]

16. Shamberger, R.J.; Willis, C.E. Selenium Distribution and Human Cancer Mortality. CRC Crit. Rev. Clin. Lab. Sci. 1971, 2, $211-221$. [CrossRef]

17. Goodman, G.E.; Schaffer, S.; Bankson, D.D.; Hughes, M.P.; Omenn, G.S. Carotene and Retinol Efficacy Trial Co-Investigators Predictors of Serum Selenium in Cigarette Smokers and the Lack of Association with Lung and Prostate Cancer Risk. Cancer Epidemiol Biomark. Prev. 2001, 10, 1069-1076.

18. Górska, S.; Maksymiuk, A.; Turło, J. Selenium-Containing Polysaccharides-Structural Diversity, Biosynthesis, Chemical Modifications and Biological Activity. Appl. Sci. 2021, 11, 3717. [CrossRef]

19. Mizuno, M.; Nishitani, Y. Immunomodulating Compounds in Basidiomycetes. J. Clin. Biochem. Nutr. 2013, 52, 202-207. [CrossRef]

20. Yang, D.; Zhou, Z.; Zhang, L. An Overview of Fungal Glycan-Based Therapeutics. In Progress in Molecular Biology and Translational Science; Elsevier: Amsterdam, The Netherlands, 2019; Volume 163, pp. 135-163. ISBN 978-0-12-817740-2.

21. Zhang, M.; Zhang, Y.; Zhang, L.; Tian, Q. Mushroom Polysaccharide Lentinan for Treating Different Types of Cancers: A Review of 12 Years Clinical Studies in China. Prog. Mol. Biol. Transl. Sci. 2019, 163, 297-328. [CrossRef] [PubMed]

22. DeVere White, R.W.; Hackman, R.M.; Soares, S.E.; Beckett, L.A.; Sun, B. Effects of a Mushroom Mycelium Extract on the Treatment of Prostate Cancer. Urology 2002, 60, 640-644. [CrossRef]

23. Yoshino, S.; Nishikawa, K.; Morita, S.; Takahashi, T.; Sakata, K.; Nagao, J.; Nemoto, H.; Murakami, N.; Matsuda, T.; Hasegawa, H.; et al. Randomised Phase III Study of S-1 Alone versus S-1 plus Lentinan for Unresectable or Recurrent Gastric Cancer (JFMC36-0701). Eur. J. Cancer 2016, 65, 164-171. [CrossRef]

24. Malinowska, E.; Klimaszewska, M.; Strączek, T.; Schneider, K.; Kapusta, C.; Podsadni, P.; Łapienis, G.; Dawidowski, M.; Kleps, J.; Górska, S.; et al. Selenized Polysaccharides-Biosynthesis and Structural Analysis. Carbohydr. Polym. 2018, 198, 407-417. [CrossRef]

25. Kaleta, B.; Górski, A.; Zagożdżon, R.; Cieślak, M.; Kaźmierczak-Barańska, J.; Nawrot, B.; Klimaszewska, M.; Malinowska, E.; Górska, S.; Turło, J. Selenium-Containing Polysaccharides from Lentinula edodes-Biological Activity. Carbohydr. Polym. 2019, 223, 115078. [CrossRef]

26. Osemwegie, O.O.; Adetunji, C.O.; Ayeni, E.A.; Adejobi, O.I.; Arise, R.O.; Nwonuma, C.O.; Oghenekaro, A.O. Exopolysaccharides from Bacteria and Fungi: Current Status and Perspectives in Africa. Heliyon 2020, 6, e04205. [CrossRef] [PubMed] 
27. Sharma, S.; Khanna, P.K.; Kapoor, S. Optimised Isolation of Polysaccharides from Lentinula edodes Strain NCBI JX915793 Using Response Surface Methodology and Their Antibacterial Activities. Nat. Prod. Res. 2016, 30, 616-621. [CrossRef]

28. Wu, X.J.; Hansen, C. Antioxidant Capacity, Phenolic Content, and Polysaccharide Content of Lentinus edodes Grown in Whey Permeate-Based Submerged Culture. J. Food Sci. 2007, 73, M1-M8. [CrossRef] [PubMed]

29. García-Cruz, F.; Durán-Páramo, E.; Garín-Aguilar, M.A.; Valencia del Toro, G.; Chairez, I. Parametric Characterization of the Initial PH Effect on the Polysaccharides Production by Lentinula edodes in Submerged Culture. Food Bioprod. Process. 2020, 119, 170-178. [CrossRef]

30. Lo, T.C.T.; Kang, M.W.; Wang, B.C.; Chang, C.A. Glycosyl Linkage Characteristics and Classifications of Exo-Polysaccharides of Some Regionally Different Strains of Lentinula edodes by Amplified Fragment Length Polymorphism Assay and Cluster Analysis. Anal. Chim. Acta 2007, 592, 146-153. [CrossRef]

31. He, P.; Geng, L.; Mao, D.; Xu, C. Production, Characterization and Antioxidant Activity of Exopolysaccharides from Submerged Culture of Morchella Crassipes. Bioprocess Biosyst. Eng. 2012, 35, 1325-1332. [CrossRef] [PubMed]

32. Adeeyo, A.O.; Lateef, A.; Gueguim-Kana, E.B. Optimization of the Production of Extracellular Polysaccharide from the Shiitake Medicinal Mushroom Lentinus edodes (Agaricomycetes) Using Mutation and a Genetic Algorithm-Coupled Artificial Neural Network (GA-ANN). Int. J. Med. Mushrooms 2016, 18, 571-581. [CrossRef]

33. Lee, J.Y.; Kim, J.Y.; Lee, Y.G.; Rhee, M.H.; Hong, E.K.; Cho, J.Y. Molecular Mechanism of Macrophage Activation by Exopolysaccharides from Liquid Culture of Lentinus edodes. J. Microbiol. Biotechnol. 2008, 18, 355-364. [CrossRef]

34. Yang, B.-K.; Kim, D.-H.; Jeong, S.-C.; Das, S.; Choi, Y.-S.; Shin, J.-S.; Lee, S.-C.; Song, C.-H. Hypoglycemic Effect of a Lentinus Edodes Exo-Polymer Producedfrom a Submerged Mycelial Culture. Biosci. Biotechnol. Biochem. 2002, 66, 937-942. [CrossRef] [PubMed]

35. Belton, P.S.; Colquhoun, I.J.; Grant, A.; Wellner, N.; Field, J.M.; Shewry, P.R.; Tatham, A.S. FTIR and NMR Studies on the Hydration of a High-Mr Subunit of Glutenin. Int. J. Biol. Macromol. 1995, 17, 74-80. [CrossRef]

36. Gutiérrez, A.; Prieto, A.; Martínez, A.T. Structural Characterization of Extracellular Polysaccharides Produced by Fungi from the Genus Pleurotus. Carbohydr. Res. 1996, 281, 143-154. [CrossRef]

37. Šandula, J.; Kogan, G.; Kačuráková, M.; Machová, E. Microbial $(1 \rightarrow 3)-\beta$-D-Glucans, Their Preparation, Physico-Chemical Characterization and Immunomodulatory Activity. Carbohydr. Polym. 1999, 38, 247-253. [CrossRef]

38. Chen, J.; Zhou, J.; Zhang, L.; Nakamura, Y.; Norisuye, T. Chemical Structure of the Water-Insoluble Polysaccharide Isolated from the Fruiting Body of Ganoderma Lucidum. Polym. J. 1998, 30, 838-842. [CrossRef]

39. Unursaikhan, S.; Xu, X.; Zeng, F.; Zhang, L. Antitumor Activities of $O$-Sulfonated Derivatives of $(1 \rightarrow 3)$ - $\alpha$-D-Glucan from Different Lentinus edodes. Biosci. Biotechnol. Biochem. 2006, 70, 38-46. [CrossRef]

40. Wang, T.; Deng, L.; Li, S.; Tan, T. Structural Characterization of a Water-Insoluble $(1 \rightarrow 3)$ - $\alpha$-D-Glucan Isolated from the Penicillium Chrysogenum. Carbohydr. Polym. 2007, 67, 133-137. [CrossRef]

41. Kacuráková, M. FT-IR Study of Plant Cell Wall Model Compounds: Pectic Polysaccharides and Hemicelluloses. Carbohydr. Polym. 2000, 43, 195-203. [CrossRef]

42. Silverstein, R.M.; Webster, F.X.; Kiemle, D.J.; Jankowski, S.; Potrzebowski, M.; Sochacki, M. Spektroskopowe Metody Identyfikacji Związów Organicznych; Wydawnictwo Naukowe PWN: Warsaw, Poland, 2012; ISBN 978-83-01-15071-6.

43. Yap, A.-T.; Ng, M.-L. An Improved Method for the Isolation of Lentinan from the Edible and Medicinal Shiitake Mushroom, Lentinus edodes (Berk.) Sing.(Agaricomycetideae). Int. J. Med. Mushrooms 2001, 3, 9-20. [CrossRef]

44. Malinowska, E.; Krzyczkowski, W.; Herold, F.; Łapienis, G.; Ślusarczyk, J.; Suchocki, P.; Kuraś, M.; Turło, J. Biosynthesis of Selenium-Containing Polysaccharides with Antioxidant Activity in Liquid Culture of Hericium Erinaceum. Enzym. Microb. Technol. 2009, 44, 334-343. [CrossRef]

45. Bock, K.; Pedersen, C. Carbon-13 Nuclear Magnetic Resonance Spectroscopy of Monosaccharides. In Advances in Carbohydrate Chemistry and Biochemistry; Elsevier: Amsterdam, The Netherlands, 1983; Volume 41, pp. 27-66. ISBN 978-0-12-007241-5.

46. Gerwig, G.J.; Kamerling, J.P.; Vliegenthart, J.F.G. Determination of the Absolute Configuration of Monosaccharides in Complex Carbohydrates by Capillary G.L.C. Carbohydr. Res. 1979, 77, 1-7. [CrossRef]

47. Gorin, P.A.J.; Mazurek, M. Further Studies on the Assignment of Signals in ${ }^{13}$ C Magnetic Resonance Spectra of Aldoses and Derived Methyl Glycosides. Can. J. Chem. 1975, 53, 1212-1223. [CrossRef]

48. Górska, S.; Sandstrőm, C.; Wojas-Turek, J.; Rossowska, J.; Pajtasz-Piasecka, E.; Brzozowska, E.; Gamian, A. Structural and Immunomodulatory Differences among Lactobacilli Exopolysaccharides Isolated from Intestines of Mice with Experimentally Induced Inflammatory Bowel Disease. Sci. Rep. 2016, 6, 37613. [CrossRef] [PubMed]

49. Mandal, E.K.; Maity, K.; Maity, S.; Gantait, S.K.; Behera, B.; Maiti, T.K.; Sikdar, S.R.; Islam, S.S. Chemical Analysis of an Immunostimulating $(1 \rightarrow 4)-,(1 \rightarrow 6)$-Branched Glucan from an Edible Mushroom, Calocybe Indica. Carbohydr. Res. 2012, 347, 172-177. [CrossRef]

50. Katzenellenbogen, E.; Kocharova, N.A.; Toukach, P.V.; Górska, S.; Korzeniowska-Kowal, A.; Bogulska, M.; Gamian, A.; Knirel, Y.A. Structure of an Abequose-Containing O-Polysaccharide from Citrobacter Freundii O22 Strain PCM 1555. Carbohydr. Res. 2009, 344, 1724-1728. [CrossRef]

51. Kobayashi, Y.; Ogra, Y.; Ishiwata, K.; Takayama, H.; Aimi, N.; Suzuki, K.T. Selenosugars Are Key and Urinary Metabolites for Selenium Excretion within the Required to Low-Toxic Range. Proc. Natl. Acad. Sci. USA 2002, 99, 15932-15936. [CrossRef] 
52. Chen, Y.; Mao, W.-J.; Yan, M.-X.; Liu, X.; Wang, S.-Y.; Xia, Z.; Xiao, B.; Cao, S.-J.; Yang, B.-Q.; Li, J. Purification, Chemical Characterization, and Bioactivity of an Extracellular Polysaccharide Produced by the Marine Sponge Endogenous Fungus Alternaria sp. SP-32. Mar. Biotechnol. 2016, 18, 301-313. [CrossRef]

53. Sandal, I.; Inzana, T.J.; Molinaro, A.; Castro, C.D.; Shao, J.Q.; Apicella, M.A.; Cox, A.D.; Michael, F.S.; Berg, G. Identification, Structure, and Characterization of an Exopolysaccharide Produced by Histophilus Somni during Biofilm Formation. BMC Microbiol. 2011, 11, 186. [CrossRef]

54. Molinaro, A.; Piscopo, V.; Lanzetta, R.; Parrilli, M. Structural Determination of the Complex Exopolysaccharide from the Virulent Strain of Cryphonectria Parasitica. Carbohydr. Res. 2002, 337, 1707-1713. [CrossRef]

55. Ray, S.; Das, T. Theory of Angle-Dependent Marginal Fermi Liquid Self-Energy and Its Existence at All Dopings in Cuprates. J. Phys. Condens. Matter. 2019, 31, 365603. [CrossRef]

56. Zhang, X.; Pápai, M.; Møller, K.; Zhang, J.; Canton, S. Characterizing the Solvated Structure of Photoexcited [Os(Terpy)2]2+ with X-Ray Transient Absorption Spectroscopy and DFT Calculations. Molecules 2016, 21, 235. [CrossRef]

57. Mahapatra, S.; Banerjee, D. Fungal Exopolysaccharide: Production, Composition and Applications. Microbiol. Insights 2013, 6, MBI-S10957. [CrossRef] [PubMed]

58. Klimaszewska, M.; Górska, S.; Łapienis, G.; Kaleta, B.; Górska, S.; Kaszowska, M.; Dawidowski, M.; Gamian, A.; Zagożdżon, R.; Górski, A.; et al. Identification of the Primary Structure of Selenium-Containing Polysaccharides Selectively Inhibiting T-Cell Proliferation. Molecules 2021, 26, 5404. [CrossRef]

59. Elisashvili, V.; Wasser, S.P.; Tan, K.-K.; Chichua, D.; Kachlishvili, E. Extracellular Polysaccharide Production by Culinary-Medicinal Shiitake Mushroom Lentinus edodes (Berk.) Singer and Pleurotus (Fr.) P. Karst. Species Depending on Carbon and Nitrogen Source. Int. J. Med. Mushrooms 2004, 6, 165-172. [CrossRef]

60. Chen, T.; Zheng, W.; Wong, Y.-S.; Yang, F.; Bai, Y. Accumulation of Selenium in Mixotrophic Culture of Spirulina Platensis on Glucose. Bioresour. Technol. 2006, 97, 2260-2265. [CrossRef] [PubMed]

61. Ye, S.; Zhang, J.; Liu, Z.; Zhang, Y.; Li, J.; Li, Y.O. Biosynthesis of Selenium Rich Exopolysaccharide (Se-EPS) by Pseudomonas PT-8 and Characterization of Its Antioxidant Activities. Carbohydr. Polym. 2016, 142, 230-239. [CrossRef]

62. Chihara, G.; Hamuro, J.; Maeda, Y.Y.; Arai, Y.; Fukuoka, F. Fractionation and Purification of the Polysaccharides with Marked Antitumor Activity, Especially Lentinan, from Lentinus edodes (Berk.) Sing.(an Edible Mushroom). Cancer Res. 1970, 30, $2776-2781$. [PubMed]

63. Turlo, J.; Gutkowska, B.; Herold, F.; Dawidowski, M.; Słowiński, T.; Zobel, A. Relationship between Selenium Accumulation and Mycelial Cell Composition in Lentinula edodes (Berk.) Cultures. J. Toxicol. Environ. Health Part A 2010, 73, 1211-1219. [CrossRef]

64. Staub, A.M. Removeal of Protein-Sevag Method. Methods Carbohydr. Chem. 1965, 5, 5-6.

65. Qu, C.; Yu, S.; Jin, H.; Wang, J.; Luo, L. The Pretreatment Effects on the Antioxidant Activity of Jujube Polysaccharides. Spectrochim. Acta Part A Mol. Biomol. Spectrosc. 2013, 114, 339-343. [CrossRef] [PubMed]

66. Komura, D.L.; Ruthes, A.C.; Carbonero, E.R.; Alquini, G.; Rosa, M.C.C.; Sassaki, G.L.; Iacomini, M. The Origin of Mannans Found in Submerged Culture of Basidiomycetes. Carbohydr. Polym. 2010, 79, 1052-1056. [CrossRef]

67. Lemieszek, M.K.; Nunes, F.M.; Rzeski, W. Branched Mannans from the Mushroom Cantharellus Cibarius Enhance the Anticancer Activity of Natural Killer Cells against Human Cancers of Lung and Colon. Food Funct. 2019, 10, 5816-5826. [CrossRef]

68. Carlile, M.J.; Watkinson, S.C.; Gooday, G.W. The Fungi, 2nd ed.; Academic Press: San Diego, CA, USA, 2001; ISBN 978-0-12738445-0.

69. Kim, G. Purification and Characterization of Acidic Proteo-Heteroglycan from the Fruiting Body of Phellinus linteus (Berk. \& M.A. Curtis) Teng. Bioresour. Technol. 2003, 89, 81-87. [CrossRef] [PubMed]

70. Li, J.; Liu, Y.; Fan, L.; Ai, L.; Shan, L. Antioxidant Activities of Polysaccharides from the Fruiting Bodies of Zizyphus Jujuba Cv. Jinsixiaozao. Carbohydr. Polym. 2011, 84, 390-394. [CrossRef]

71. Xiao, Y. Mesenchymal Stem Cells; Nova Science Publishers: New York, NY, USA, 2012; ISBN 978-1-61324-669-6.

72. Klimaszewska, M.; Górska, S.; Dawidowski, M.; Podsadni, P.; Szczepanska, A.; Orzechowska, E.; Kurpios-Piec, D.; GrosickaMaciag, E.; Rahden-Staron, I.; Turło, J. Selective Cytotoxic Activity of Se-Methyl-Seleno-L-Cysteine-and Se-PolysaccharideContaining Extracts from Shiitake Medicinal Mushroom, Lentinus edodes (Agaricomycetes). Int. J. Med. Mushrooms 2017, 19, 709-716. [CrossRef] [PubMed]

73. Lindahl-Kiessling, K.; Peterson, R.D.A. The Mechanism of Phytohemagglutinin (PHA) Action. Exp. Cell Res. 1969, 55, 85-87. [CrossRef]

74. Van Wauwe, J.P.; De Mey, J.R.; Goossens, J.G. OKT3: A Monoclonal Anti-Human T Lymphocyte Antibody with Potent Mitogenic Properties. J. Immunol. 1980, 124, 2708-2713. [CrossRef]

75. Turlo, J.; Gutkowska, B.; Herold, F. Effect of Selenium Enrichment on Antioxidant Activities and Chemical Composition of Lentinula edodes (Berk.) Pegl. Mycelial Extracts. Food Chem. Toxicol. 2010, 48, 1085-1091. [CrossRef]

76. Turło, J.; Gutkowska, B.; Herold, F.; Gajzlerska, W.; Dawidowski, M.; Dorociak, A.; Zobel, A. Biological Availability and Preliminary Selenium Speciation in Selenium-Enriched Mycelium of Lentinula edodes (Berk.). Food Biotechnol. 2011, 25, 16-29. [CrossRef]

77. Cheong, K.-L.; Wu, D.-T.; Zhao, J.; Li, S.-P. A Rapid and Accurate Method for the Quantitative Estimation of Natural Polysaccharides and Their Fractions Using High Performance Size Exclusion Chromatography Coupled with Multi-Angle Laser Light Scattering and Refractive Index Detector. J. Chromatogr. A 2015, 1400, 98-106. [CrossRef] 
78. Pedro, J.; Andrade, F.; Magni, D.; Tudino, M.; Bonivardi, A. On-Line Submicellar Enhanced Fluorometric Determination of Se(IV) with 2,3-Diaminonaphthalene. Anal. Chim. Acta 2004, 516, 229-236. [CrossRef]

79. Bradford, M.M. A Rapid and Sensitive Method for the Quantitation of Microgram Quantities of Protein Utilizing the Principle of Protein-Dye Binding. Anal. Biochem. 1976, 72, 248-254. [CrossRef] 